Noname manuscript No.

(will be inserted by the editor)

\title{
On Causality as the Fundamental Concept of Gödel's Philosophy
}

\author{
Srećko Kovač
}

the date of receipt and acceptance should be inserted later

\begin{abstract}
This paper proposes a possible reconstruction and philosophicallogical clarification of Gödel's idea of causality as the philosophical fundamental concept. The results are based on Gödel's published and non-published texts (including Max Phil notebooks), and are established on the ground of interconnections of Gödel's dispersed remarks on causality, as well as on the ground of his general philosophical views. The paper is logically informal but is connected with already achieved results in the formalization of a causal account of Gödel's onto-theological theory. Gödel's main causal concepts are analysed (will, force, enjoyment, God, time and space, life, form, matter). Special attention is paid to a possible causal account of some of Gödel's logical concepts (assertion, privation, affirmation, negation, whole, part, general, particular, subject, predicate, necessary, possible, implication), as well as of logical antinomies. The problem of mechanical and non-mechanical procedures in the work with and on concepts is addressed in terms of Gödel's causal view.
\end{abstract}

MSC 01260, 03A05

Keywords Kurt Gödel · Causality · Primitive concepts · Will · Force · Logic $\cdot$ General $\cdot$ Whole $\cdot$ Subject $\cdot$ Human mind

\section{Introduction - cause as the fundamental concept}

In this paper we focus on Gödel's idea of causality as the philosophical fundamental concept (der Grundbegriff) and propose an interpretation of some characteristic details of Gödel's causal philosophy with respect, in particular,

Institute of Philosophy

a public research institute of the Republic of Croatia

Ul. grada Vukovara 54, Zagreb, Croatia

E-mail: skovac@ifzg.hr 
to his philosophy of logic. ${ }^{1}$ Although the available textual basis for such a reconstruction is scarce and fragmentary, one general line of Gödel's thought is detectable that points to a causal foundation and explanation of primitive philosophical and logical concepts. In addition, a number of places in Gödel's text that do not explicitly mention causality can be put in relation with his statements made in explicit causal terms. Hence, it seems reasonable to try to summarize what is available in scattered remarks of Gödel into one comprehensive picture. This picture will be related to some of Gödel's versions of a possible onto-theological axiomatization (Gödel, 1995d), with the intention to give here a broader, informal philosophical context for these drafts.

Text sources for this reconstruction are Gödel's Collected Works (Gödel, 1986-2003), Gödel's reflections as published in Wang (1996, 1987) and Toledo (2011), Gödel's manuscript Max X (Crocco et al, 2017), a draft of the transcriptions of manuscripts Phil XIV and Max XV (Gödel, 2016), as well as materials from Crocco and Engelen (2016a), which contains many of Gödel's remarks from his Max Phil notebooks. ${ }^{2}$ Methodologically, whenever possible, we try to reconstruct Gödel's own view on the ground of his text. Otherwise, possible views are proposed or suggested based on the text and on objectively present interconnections between Gödel's remarks.

It should be noted that Gödel's Max Phil manuscripts, which we make use of, were not aimed for publication, especially because of the "esoteric" nature of many reflections contained therein, by far departing from mainstream philosophy and science. However, they offer many deep insights of Gödel's that are relevant for this paper's topic. ${ }^{3}$

Causality as a primitive concept is confirmed by Gödel's statements from different periods of his work, and, as stated in the quotations below in this section, has a fundamental role. According to Gödel's method (which includes "idealization" by "disregarding the imprecision in what is actual"), new and

\footnotetext{
1 A formalization of a causal account of Gödel's onto-theology is proposed in Kovač (2012, 2015), in connection with the discussion (philosophical and technical) on the so-called modal collapse.

2 Many reflections from Wang $(1996,1987)$ and the reflections from Toledo (2011) stem from the 1970s; the manuscript Max X was written from March 1943 to January 1944, Phil XIV from July 1946 to May 1955, and Max XV from May 1955 and thereafter. For the datation of Max Phil manuscripts, see Crocco and Engelen (2016b). In light of further investigation and publication of Gödel's manuscripts, we can expect new clarifications of Gödel's related views.

3 According to Gödel, "true philosophy" (Wang, 1996, 9.3.16 p. 307, 9.3.21 p. 308) cannot be communicated to others as a "propositional knowledge" - what can be communicated is only the method used, "attitude of mind" (Wang, 1996, 5.3.30-31 pp. 169-170, 5.3.35 and 5.3 .37 p. 171). Moreover, the publication of "true philosophy" would be "contrary to the world" and quite unsafe for the author (Wang, 1996, 9.3.16 p. 307, cf. 5.3 .8 p. 166). Although aiming at "true philosophy", Gödel does not claim ever to have arrived at some absolute philosophical truths (Wang, 1996, 5.3.30 p. 170). Yet, he held the opinion that philosophers such as Kant and Husserl arrived at "true philosophy" ("absolute knowledge", "superscience") but did not publish it. See footnote 126, p. 36 below, Wang (1996, pp. 166, 167, 169-171, 307, 308), and Kovač (2008, pp. 149-150). For Leibniz, see Wang (1996, p. 307 ) and Wang (1987, pp. 103-104, 224, 311).
} 
new primitive concepts can be discovered, ${ }^{4}$ just as some of the primitive concepts can eventually be found to be definable in terms of other concepts, as fundamental ones. ${ }^{5}$ Although Wang reports that Gödel said to him "on several occasions" in the seventies that he "was not able to decide what the primitive concepts of philosophy are" (Wang, 1996, p. 120, cf. p. 288), "causality" seems to be almost constantly present on Gödel's lists of primitive concepts. It should be mentioned that it does not appear in the lists concerned with specific logical primitive concepts, nor in the list segment reported in Toledo (2011) and van Atten and Kennedy (2003, p. 433), although the concepts listed in this list segment are, for Gödel, essentially connected with causality, as will be shown below.

In this paper, we claim that Gödel was seriously considering causality as the fundamental concept of philosophy and, possibly, of logic (a reduction of all primitive concepts to only one of them). According to his general attitude, Gödel did not understand this idea as some definitely obtained truth (see footnote 3, p. 2), and was permanently engaged in a search for philosophical and logical foundations. With this caveat, a causal interpretation of Gödel's philosophy, including philosophy of logic, will be proposed, with its primitive concepts causally understood. The view on logic as founded on the concept of causality will be termed 'logical causalism'.

We now refer to some of Gödel's reflections that most explicitly confirm his idea of philosophy as based on the concept of causality. In Phil XIV, ${ }^{7}$ we find the following statement:

\footnotetext{
${ }^{4}$ See Wang (1996, 9.2.19 p. 300, 9.2.22 p. 301).

5 We will sometimes call primitive concepts "basic" concepts, to possibly avoid the strong connotation of their definite irreducibility. In Gödel's usage, "primitive concepts", "primitive notions" (Grundbegriffe; cf. "main categories", Wang 1996, 5.3 .7 p. 166), are, first, undefined concepts of some theory with axioms that "follow from the meaning of the primitive terms under consideration" (Gödel, 1995f, p. 321). Secondly, "primitive concepts" are also concepts philosophically considered to be fundamental, independently of given axiomatic systems ("fundamental concepts"; Gödel 1995a, p. 337, Gödel 1990d, p. 121). Cf. Russell's distinction between "undefined" and "indefinable ideas" (Gödel, 1986-2003, vol. 1, p. 44, introductory note by B. Dreben and J. van Heijenoort). In general, Gödel allows for a possibility that primitive concepts could once become defined in terms of "more fundamental" or "undefinable" ones ("irreducible to anything more fundamental"; Gödel 1990d, p. 139). Regarding the "concept" itself, as will be shown later, its intended meaning is "just generality" (p. 28) but seems to be connected with some essential difficulties regarding its possible axiomatic description (see subsection 3.3).

${ }^{6}$ However, with respect to the theory of concepts (logic proper), Wang reports Gödel as saying, "[W]e know what the primitives of the theory are which cannot be reduced to anything more primitive" (Wang, 1996, 8.5.13 p. 272). - Gödel uses the term 'logic' sometimes in a broader sense, comprising theory of concepts (intensional logic) as well as mathematical logic (extensional, including set theory), and sometimes narrowly, in the sense of the theory of concepts. We will focus on logic in the latter (occasionally considered as strict) sense. See Wang $(1996,8.4 .18$ p. 268 , 8.6.1 p. 274). For the inclusive sense of 'logic', see also in Gödel (1995a, p. 334, ftn. 2).

7 When citing Gödel's original pagination, 'p' for 'page' will be omitted.
} 
The philosophical fundamental concept is cause. (Der philosophische Grundbegriff is die Ursache.)

(Gödel, 1995d, p. 432; Gödel, 2016, XIV 104; cf. Wang, 1996, p. $119,9.1 .18$ p. $294,9.4 .16$ p. 315 , dated 1954$)$

Gödel repeats this view on causation within the context of his philosophy of force and fact of the 1970s:

Causation is fundamental; it should also explain the general and the particular.

(Wang, 1996, 9.4.5 p. 312)

It should be noted that, according to Gödel, the general and the particular themselves constitute what is a "fundamental fact of reality" (Wang, 1996, p. $295) .{ }^{8}$ In addition, Gödel writes (6 October 1961, a letter to his mother) about

the principle that everything has a cause, on which the whole science rests (Gödel, 1986-2003, IV pp. 438-439) ${ }^{9}$

and to which the "theological worldview" that "everything in the world has a meaning" is "exactly analogous" (Wang, 1996, p. 108). ${ }^{10}$ Accordingly, in a reflection from the 1970s, Gödel remarks that causation is the foundation of time:

the real idea behind time is causation; the time structure of the world is just its causal structure. (Wang, 1996, 9.5.6 p. 320, 5.3.23 p. 168)

Finally, causality is essential in the concept of understanding:

Understanding is ... a step in the direction of reduction to the last cause. (Wang 1996, 7.3 .12 p. 235; see below footnote 118, p. 35)

A chronological note. Although the oldest of the above remarks stems, most probably, from 1954, the roots of Gödel's tenet of causality could be traced back to much earlier times, before 1943, when Gödel began his systematic study of Leibniz (1943-1946; see Gödel 1986-2003, vol. 4, p. 450). On the other hand, this tenet was retained and further developed after he began an intensive study of Husserl (in 1959; Wang 1987, p. 121; Wang 1996, p. 80), for whom causality was not a primary concern. ${ }^{11}$ We mention some aspects of the concept of causality that have, or most probably have, their origins in Gödel's philosophy prior to his systematic study of Leibniz. This study influenced Gödel to apply a modified monadological view on causality (monads as bearers of forces, drives, and representations; God as the "central monad"). ${ }^{12}$ (1) The reduction of time to a causal structure of the world originates from

\footnotetext{
8 See below footnote 90 on p. 27.

9 Cf. Wang (1996, p. 108) and Wang (1987, p. 217).

10 Cf. Wang (1987, p. 217). See Kovač (2015, pp. 163-164).

11 See Tieszen (2016, pp. 455-456). For Gödel's critique of Husserl's subjectivism, see van Atten (2015, pp. 122-124) or van Atten and Kennedy (2003); cf. Wang (1987, p. 219).

12 "My theory ... is like the monadology by Leibniz in its general structure" (Wang, 1996, 0.2 .1 p. 8 , emphasis added).
} 
Gödel's comparison of Kant and Einstein's relativity theory - this comparison "always interested" him (Wang, 1987, p. 38, letter to his mother on 7 November 1947). On such basis, Gödel speaks about "Einstein-Kantian conception of time", where there is no real lapse of time - past events are as actual (wirklich) as present ones (Max X, in Crocco et al 2017, 23; later, e.g., in Gödel 1995g,b, 1990b; see Audireau 2016, pp. 59-60). ${ }^{13}$ (2) Gödel's view that Kant's "things in themselves" causally "affect" our senses, as expressed in texts from 1946 to 1949 (Gödel, 1995g, pp. 232, 248, 259, cf. ftn. 3 on p. 230, and p. 236) could probably be applied also to Gödel's earlier understanding of Kant, whom he had already studied in secondary school in 1922 (Gödel, 1986-2003, vol. 4, pp. $447,449)$. In addition, Gödel's acceptance of attractive and repulsive forces or "drives" (Crocco et al 2017, 6, 14; Wang 1996, 9.1.8 p. 292), retained also after his study of Leibniz, may have its origin in Kant's natural philosophy (Bernard, 2016, p. 98, ftn. 33), with which Gödel seems to have been acquainted since 1925 (Wang, 1996, pp. 68-69). (3) Gödel's "conceptual realism" (Platonism), adopted in 1925 (Gödel, 1986-2003, vol. 4, pp. 447, 450), is not just "objective idealism" but may also include the idea of the causal influence of concepts on objects - at least as confirmed in Max IX (November 1942 March 1943) (Crocco, 2016). (4) "Soul", intellect, and cognitive subject ("I") as causal (wirkend) components are mentioned in Max VI (July 1942, Remark 381, in Engelen 2016, p. 179, ftn. 33). In addition, Gödel's ideas on "working" intellect can be traced back to Aristotle and Thomas Aquinas (Engelen, 2013, 2016). We will come to these aspects in more detail later (see p. 34, including footnote 113).

\section{Primitive concepts and causality}

In this section, some Gödel's primitive philosophical concepts are analysed with respect to their causal meaning. The focus will be on the concepts that Gödel, in a remark from the 1950s (cf. reflection (1) above), considers as involved by the concept of cause. Some remarks on Gödel's late philosophy of force and fact will be added in light of its relevance for a possible causal foundations of philosophy.

\subsection{Primitive concepts}

Let us return to Gödel's above-mentioned note where causality is referred to as "the fundamental philosophical concept", to see which concepts he mentions as "involved" by "causality":

\footnotetext{
13 Cf. also the distinction between the category of causality and a subjective concept of causality, limited to the "effect in time" (Gödel, 2016, XIV 45). On Gödel's philosophy of time in relation to Einsteins relativity theory, see extensively in Yourgrau $(1999,2005)$.
} 
The philosophical fundamental concept is cause. It involves: will ${ }^{x}$, force, enjoyment ${ }^{x}$, God, time, space* .

${ }^{x}$ Hence life and affirmation and negation. ${ }^{*}$ Being near $=$ possibility of influence.

Perhaps the other Kantian categories (that is, the logical ones, including necessity) can be defined in terms of causality, and the logical (set theoretical) axioms can be derived from the axioms of causality. ... (Gödel 1995d, pp. 432-435, slightly modified translation, cf. Gödel 2016, XIV 104-105)

"Will", "force", "enjoyment", "God", "time", "space", "life", "affirmation", and "negation" are introduced in the above reflection as basic philosophical concepts with more or less obvious causal sense. Gödel is cautious with Kantian categories, conceived as basic logical concepts, ${ }^{14}$ asserting that perhaps the rest of them (beside "affirmation", "negation", and "possibility", which are already mentioned in (3)), too, could be reduced to causal terms. We will come to this question in Section 3.2, p. 23.

Many concepts mentioned in remark (3) are also recognizable in the following list of primitive concepts (handwritten page "Philosophical Remarks", around 1960, according to Wang): ${ }^{15}$

reason, cause, substance, accidens, necessity (conceptual), value-harmony (positiveness), God (= last principle), cognition, force, volition, time, form, content, matter, life, truth, class (= absolute), concept (general and individual), idea, reality, possibility, irreducible, many and one, essence.

(Wang, 1996, p. 315)

Of course, some of these or closely related concepts are interdefinable in various formal systems, for example, "necessity" and "possibility" in standard modal logic, or "positiveness" and "to be God" in Gödel's onto-theological system from 1970 (Gödel, 1995d, p. 403).

Several other of Gödel's, possibly only "initial", lists of primitive concepts, too, include "causality" and "substance". In one reflection, Gödel mentions "main categories",

e.g., causation, substance, action,

and "their interrelations" (Wang, 1996, 5.3.7 p. 166). In discussing Wittgenstein's philosophy, the following "philosophical concepts" are named:

apriority, causality, substance, the general concept of proof, etc.

(Wang, 1996, 5.5.5a p. 179)

\footnotetext{
14 For Kant, all categories have formal-logical origin, since they originate from basic logical forms of judgements ("table of judgements"; see Kant 1968, B105, translated in Kant 1998). As applied to what is given in an intuition, categories receive "transcendental-logical" (i.e., ontological) status.

15 E.g., "space" is missing, while "enjoyment" could be assumed as implicit in "life" in the sense of remark (3).
} 
Additionally, according to Wang, Gödel mentions "object, concept, substance, cause and sometimes a few others" as "primitive concepts" (Wang, 1987, p. 192), and suggests "God as one of the primitive concepts of metaphysics" (Wang, 1987, p. 150).

As noticed, "causality" does not explicitly appear in the list segment reported by Sue Toledo. In her conversation with Gödel, she recorded the following primitive concepts:

'object', 'relation', 'will', 'good', etc.

(van Atten 2015, p. 102;

van Atten and Kennedy 2003, p. 433; Toledo 2011, p. 200) ${ }^{16}$

Some of the primitive concepts appear also as the most general concepts in Gödel's division of "things" (beings, entities), i.e., of "unities", into objects and concepts (Wang, 1996, 9.1.25 p. 295). ${ }^{17}$

Gödel's above lists differ from the lists that we encounter, for example, in Plato, Aristotle, Leibniz or Kant, despite partial overlappings and possible inspirations by these philosophers. Variations of Gödel's (partial) lists witness his genuine search for primitive concepts, by a method of "idealization", which he saw outlined in Kant and Plato, and further precised in Husserl. ${ }^{18}$

According to Gödel, the meaning of primitive concepts and the relations among them should be described and "explained" (cf. Wang 1996, 9.4.5 p. 312) by axioms. ${ }^{19}$ This is what Gödel has in mind by requiring that a theory has to be built for philosophy (metaphysics) in analogy with Newton's axiomatization of physics (Wang, 1996, 5.3.11 p. 167). According to Gödel, to discover these axioms we should gradually clarify the meaning of primitive concepts - not by means of giving definitions, but by means of a phenomenological study of our acts and powers in the use of these concepts (cf. Gödel 1995c, pp. 382383; Wang 1996, pp. 159, 332). In this way, it should be possible to arrive at some axiomatic system of causation within which all available primitive concepts could be explained (and possibly defined by the most fundamental ones). However, "the axiomatic method goes step by step. We continue to discover new axioms; the process never finishes" (Wang, 1996, 9.1.30 p. 297). Thus, in distinction, for example, to Kant, who claimed to have systematically discovered a complete list of twelve primitive concepts (categories), Gödel looks

\footnotetext{
16 We follow van Atten and Kennedy (2003) and van Atten (2015) in having 'will' instead of 'well'. For the causal meaning of these concepts, see below subsections 2.2.1 ("will", "good"), 3.2.4, 3.2.5 and 3.4 ("object"); "relation" seems to be included in the meaning of the causation itself (cf. Ursachenrelation in Gödel 2016, XIV 18, but also "causality" as a sort of "relation" in Kant 1968, B106).

17 On one place, Wang terms the most general concepts "categories": "The basic categories of G's ontology (i.e., the 'things' or all that which exists) are objects and concepts" (Wang, 1987, p. 193). See Remark on p. 28 below.

18 See Wang (1996, 9.2.20-22 pp. 300-301) with Gödel's examples from Plato and Kant on geometric method. For Husserl's "Ideation" (Wesensschauung), see Husserl (2002, pp. 10, 138-139); cf. Wang (1987, 5.3 .7 p. 166, 7.1 .15 p. 218). In van Atten 2015, pp. 128-129 (see van Atten and Kennedy 2003, pp. 459-460), Leibniz's role is especially pointed out.

19 "The fundamental principles are concerned with what the primitive concepts are and also their relationship" (Wang, 1996, 9.1 .30 p. 297, cf. pp. 289, 244). "In a theory concepts and axioms must be combined" (Wang, 1996, 9.3.10 p. 306).
} 
upon the discovering of primitive concepts as, in a sense, similar to "empirical" work, without any guarantee to achieve completeness. ${ }^{20}$ After being acquanted with Husserl's phenomenological method, Gödel more precisely described this "empiricist" "respect" - in clear distinction to the empiricism of natural science - as "a priori psychology", ${ }^{21}$ which could be conceived as a middle way between apriorism and empiricism (in the usual sense). (On the "middle way", see Gödel 1995c, pp. $380,386.)^{22}$

\subsection{General causal structure - primitive causal concepts}

In remark (3), Gödel focuses, first, on some primitive (basic) philosophical concepts meant to be understood in causal terms. There is hardly any secure way exactly to reconstruct the explanations Gödel might have had in mind while devising this list of primitive philosophical concepts. We will look for a confirmation of his view in his different texts and remarks - if not precisely of the basically quinary causal structure of remark (3) (1. will, 2. force, 3. enjoyment, 4. God, 5. time and space), then at least of some of the components of this structure or of its traces in a possibly differently understood causal structure. $^{23}$

\footnotetext{
20 Cf. "This whole consideration incidentally shows that the philosophical implications of the mathematical facts explained do not lie entirely on the side of rationalistic or idealistic philosophy, but that in one respect they favor the empiricist viewpoint. ... [I]t suggests that the situation in mathematics is not so very different from that in the natural sciences" (Gödel, 1995f, p. 313 and ftn. 20). Cf. also Gödel's remark on "empirical content" as pertaining to the existence of "something", possibly also in mathematics (Gödel, 2016, XV, p. 64).

21 Van Atten expressed the distinction between Gödel's intended "phenomenological psychology" ("a priori psychology") and empirical psychology (on "a priori psychology", see also Toledo 2011, p. 206) in the following way: although the first one "describes mental phenomena", it "is not concerned with individual concrete facts but with invariant forms they instantiate and which delineate the range of possible concrete facts" (van Atten, 2015, p. $213)$.

22 What Gödel expected from his study of Husserl's phenomenology was a sound foundation ("thorough and systematic beginning", Wang 1996, p. 171, 9.2.6 p. 298) for a possible systematic discovery of primitive concepts (van Atten 2015, pp. 127-128/van Atten and Kennedy 2003). This in distinction to Kant's, as Gödel thought, "sloppy architectonic", which he criticized on several occasions, e.g., in Gödel (1986-2003, vol. 4, letter to Bernays from 11 May 1961, pp. 186-188). Cf. Wang (1987, p. 226). However, it should be mentioned that the paradigmatic work on the "completeness" of Kant's table of judgements by Klaus Reich (Reich 1948; Husserl being one of his teachers) seems to offer a clue to an insight into deeper foundations of Kant's architectonic.

23 Gödel often uses the term 'structure' in a general causal sense of "holding together" (zusammenhalten) and "combining" (verbinden) parts in a whole. For example, "Der Unterschied zwischen einem Haufen und einer Struktur ist, dass bei der Struktur die Teile durch die Tatsache 'verbunden' sind und diese Verbindungen selbst zur Struktur gehören" (Crocco et al, 2017, 20); "The difference between a heap and a structure is that, in the structure, the parts are 'combined' by the fact and these combinations themselves belong to the structure" [our translation]). Gödel also speaks of "the structure of a concept" (Crocco et al, 2017, 80 ), as well as of logical concepts as the structure and the "putty" that holds together parts of a given concept (footnote 87, p. 26 below). In addition, there are examples like "living structure" (Example 1 below on p. 17) and "structure of the world" in a causal or some other general sense (Wang 1996, 8.6 .10 p. 275, 5.3.8 p. 166; Gödel 1995d, p. 404; Crocco
} 
This section outlines the Gödelian causal meaning of the concepts of will, force, enjoyment, God, time and space, as well as of life, form and matter. The next section focuses on the logical aspect of the primitive concepts. Although it is not claimed that the causal components of (3), in the shape of some fundamental quinary structure of causation, remained an explicit part of Gödel's view ever after, we try to recognize this structure as at least implicitly present in his reflections from various periods (distinct periods will be clear from the citations).

It should be noticed in advance that Gödel's account of causality is highly nonconventional from the standpoint of many current views. ${ }^{24}$ Although it is based on science, it is at the same time philosophical-theological, connected with some significant philosophical views of the past (as those already mentioned), as well as with a sort of phenomenological method of intuiting concepts.

\subsubsection{Will (volition)}

Gödel characterizes will ("willing", see footnote 28, p. 10 below), most generally, as a conscious directedness towards its intentional "object". ${ }^{25}$ Will may be understood as a causal starting point, which directs (points) the causation towards something as a goal. Gödel stresses that "willing" (like cognizing) cannot be alone taken as a "fundamental concept", but only as complemented ("probably") with the "good" (das Gute) as its "object" (Crocco et al, 2017, 6970). In one of his examples, the created things always want what they think is "better". Gödel offers this as an explanation of the things' permanent creating of something new in place of what is already created, as well as an explanation, for example, of the Biblical Fall event. ${ }^{26}$ In the history of created things,

et al 2017,90). Correspondingly, we can understand the five causal components of remark (3) as constituents of a causal whole ("structure"), in which they are "combined" and "held together".

It should be noted that Husserl investigates "structures" of consciousness, noetic and noematic structures, structure of "life-experience" (Erlebnis), where 'structure' has a general meaning of 'building' (Bau, Aufbau), with a causal sense methodologically excluded (Husserl, 2002 , 1995). Of course, Gödel used the concept of structure much prior to his study of Husserl. In addition, he sometimes expresses his interest for something more than pure structures ("But 'the study of structure' is a confession that we don't know what the things are", Wang 1996, 9.1.10 p. 292). According to the analyses of this paper, this "more" could have a causal sense.

24 As will be shown, Gödel's concept of causation essentially involves a teleological aspect of "directedness" towards an end ("good").

25 "[T]he basic form of consciousness distinguishes between an intentional object and our being pointed (gerichtet) toward it in some way (feeling, willing, cognizing)" (Wang, 1996, 5.3 .28 p. 169). Cf. also footnote 61, p. 18 below. In Max XV, Gödel makes a distinction between "will" and "willing" (Wollen, related to "ought", Sollen; Gödel 2016, XV p. 66).

26 Since this is a significant note giving a broader context of Gödel's causal philosophy, it is given here, for convenience, more extensively: "Gott schuf die Dinge so, dass sie wieder ihrerseits etwas 'erschaffen' können (darauf beruht letzten Endes alle Wirkung). Vielleicht aber besteht darin der Sündenfall, dass sie nicht in diesen Zustand verharren, in dem sie Gott ursprünglich erschaffen hatte (d.h. dass sie diesen Zustand nicht gewollt $<$ haben $>$, sondern 
"what is better" might not always be reasonably conceived, and, moreover, it remains in its proper sense unrealized until the "end of time". ${ }^{27}$ In its proper, unrelativized, sense, "better" is for Gödel "the good" ("worum sich letzten Endes alles dreht", Crocco et al 2017, 70; "what everything finally revolves around" [our transl.]) and "value", that is, in Gödel's onto-theological remarks, the "positive", "perfection". 28

On the ground of Gödel's versions and sketches of ontological proof, it is possible to extract some essential properties of will. From the three ontotheological axioms about the "positive" in the sense of "perfection" (as distinguished from the "positive" as "assertion" or "attribution"), in the sketch of the ontological proof in Gödel (2016, XIV 105-107) and Gödel (1995d, pp. 434-435), it can be concluded that will, if directed towards the positive, should

1. be pointed towards a property if and only if the property does not imply a negation of a perfection; i.e., the intended property ("perfection") should be "purely good" ("A property is perfection if and only if it implies no negation of perfection"),

2. persevere in its intention towards a "perfection" irrespectively of possible contingencies of the world ${ }^{29}$ ("The necessity of a perfection is a perfection", "Or if $M \phi$ is a perfection, then $\phi$ is too"), and

3. be pointed towards "being", not towards destruction and non-being ("Being is a perfection").

In addition, since according to Gödel being implies unity, 30 "unity", too, is a perfection, and thus an intentional "object" of will.

That "being" is conceived as a "perfection", "good" and "value" is characteristic for Gödel's critical Platonism. This view overcomes Kant's dualism

'etwas Besseres'... )" (Crocco et al 2017, 12-13, emphasis added; cf. also Gödel 2016, XIV 64). "God created things so that they at their turn again 'create' something (in the end, all effect is based on this). However, the Fall may consist in this that they do not persist in the state in which God originally created them (i.e., that they did not want this state, but 'something better')" (cf. Mertens 2016, pp. 196-197, modified translation).

27 Cf. "Will is the opposite of reason" (Wang, 1996, 9.3.15 p. 307). Also, will could be ineffective (Crocco, 2016, pp. 140-141). However, the final perspective is ultimately positive: "Dieses Bessere erreichen sie auch schließlich, wenn alle Zeit zu Ende ist" (Crocco et al, 2017, 13; "They eventually reach this Better when all time is finished" [our translation]).

28 In Phil XIV, whence remark (3) is taken, "better" is an explanation of "value". The concepts of value - of "positive" and "perfection" - are crucial in Gödel's ontological argument: "The ontological proof must be grounded on the concept of value ( $p$ better than $\sim p$ ) and on the axioms" (Gödel, 1995d, pp. 432-433, also 434-435). On the "perfecting" (Vervollkommnung) and "perfection" (Vollkommenheit), which are implicitly connected with will as its intentional "object", see Crocco et al (2017, 7-8).

29 Cf. independency of the "accidental structure of the world" in Gödel (1995d, p. 404, from 1970).

30 "[D]ie Einheit ist das Wesentliche des Dinges (bedeutet das aber vielleicht nur, dass man alles als 'eines' betrachten kann)" (Gödel, 2016, XIV 81; "[T]he unity is what is essential of a thing (this may probably only mean that everything can be considered as 'one')" [our translation]). 
between theory and morals ("being" and "good") 31 but is not committed to uncritical Platonism: it does not imply that "good" causes "being". In light of Max IX (Crocco, 2016), "good", as a concept, "idea" (in distinction to a "most perfect being"), could at most choose "being" to be good-like (i.e., to "participate" in "good"). ${ }^{32}$

There are clear reasons prompting the understanding of Gödel's concept of "will" in the sense in which "will" is not only attributed to human beings or to God, but in a wider sense, as attributed to each "monad", although not to the "physical world" ("material objects") as distinguished from nature. ${ }^{33}$ This follows from Gödel's acceptance of a sort of Leibnizian monadology (see Example 2 on pp. 18-19 below), with monads having "inner life and consciousness" ("something inside"), ${ }^{34}$ and even with electrons as monads having drives and representations (Wang, 1996, 9.1.8-9 p. 292).

\subsubsection{Force}

Whereas will is just the directedness to a perfection, force is for Gödel directedness to the realization of a perfection. This includes the directedness to the realization of being, or, as Gödel expresses himself, to the "being of something". 35 Accordingly, in Max X, force is conceived as a "tendency" towards the realization of a perfection of a structure, and that in the sense that certain laws of self-preservation (i.e., of being) of the structure are obeyed (Crocco et al, 2017, 6, 7). In examples of a structure such as a pair (dipole), "electron event", and a bodily organism, Gödel describes how attractive force takes into the structure what improves the structure, while repulsive force resists and repels what would destroy the structure. In this way, attractive and repulsive forces contribute to the realization of the perfection of the structure ("maximum of the relationship between the parts" ${ }^{36}$ ) and to its self-preservation (Crocco et al, 2017, 6-8). For instance, in Gödel's remarks about "electron

\footnotetext{
31 Gödel warns of inconsistency in Kant's moral philosophy: what has no objective meaning should be subjectively (for the purpose of morals) assumed (Wang, 1996, 5.3.38-39 pp. 171172).

32 See Plato (1964-1978, VI, Republic 508E-509B, 517C), where "good" is taken to be the cause of cognition, truth, and being (and seems to be understood as a god). Also, knowledge and truth are said to be "good-like", $\dot{\alpha} \gamma \alpha \theta o \varepsilon\llcorner\delta \tilde{\eta}$ (Republic 509A).

33 See Wang (1996, 9.1.9 p. 292, 9.1.22 p. 295, 5.3.28 p. 169).

34 In Mertens (2016) it can be seen that consciousness in general has a high position in Gödel's ontological hierarchy (Max XI, from 1944): logical concepts, space and time, matter, life, consciousness, angels, ..., God. However, as in Leibniz, this does not exclude unconscious states in a monad; on "unconscious pain" and "unconscious life-experiences", see Gödel (2016, XIV 65). Cf. Leibniz (1978a, §§14, 20-21 pp. 608-609, 610) and Leibniz (1978b, $\S 4$ pp. 599-600).

35 Cf. Gödel's reflections from the 1970s, where wish, as a kind of force, is characterized by the directedness to "being something" (Wang, 1996, 9.4.7 p. 312) and "to realize something" (Wang, 1996, 9.4.3 p. 311).

36 Presumably, non-interrelated parts could act each in its own way, dissolving the whole to which they belong.
} 
events" (Crocco et al, 2017, 10, 13-15, cf. 5-6), ${ }^{37}$ force is understood as a "tendency" (more or less strong, i.e., having some magnitude) towards or against the emergence (Entstehung) of some event in the vicinity.

In addition, and in distinction to Newtonian force as a permanent "meaningless striving", Gödel's force can cease in the moment of the realization (Crocco et al, 2017, 5) as if this realization were its goal. Gödel's remarks suggest that what he has in mind is a concept of force as immanently "goaloriented" (Bernard, 2016). The acceptance of the immanent teleological nature of force coincides with Gödel's acceptance of attractive and repulsive forces, which were rejected in Leibniz's monadology and its separation of effective causes (for bodies) from teleological causes (for monads) (see Leibniz 1978a, $\S 79$ p. 620 ; Leibniz 1978 b, $\S 3$ pp. $598-599) .{ }^{38}$

\subsubsection{Enjoyment}

From Gödel's remarks, we clearly recognize that enjoyment (Genuß, Lust) is for him essentially connected with the achievement of a state where some perfection (as a goal) is realized. This can be confirmed by several examples. In a remark from the 1970s, happiness and enjoyment characterize a final human state of fulfilled goals - there is "another world where there is no sickness or death and where all marriages are happy and all work (every career) is enjoyable" (Wang, 1996, 9.4.19 p. 317). Further, since to be satisfied is included in enjoyment, we can also refer to an explanation of the causal role of enjoyment in a negative way: in the already mentioned context of the Fall (footnote 26, p. 9), Gödel explains that dissatisfaction and "insatiability" (Unersättlichkeit) prompt new creating. ${ }^{39}$ Obviously, a satisfaction with the reached state (enjoyment) corresponds with a perfection achieved.

In particular, Gödel suggests that a variety of what is realized is a ground of enjoyment (variatio delectat). ${ }^{40}$ This leads us to see that enjoyment corresponds to "harmony" (Gödel, 1995d, pp. 432-433), as a realized unity in the

\footnotetext{
37 See also Bernard (2016, pp. 100-104).

38 See Bernard (2016, p. 98). According to Leibniz, some laws of motion need a teleological explanation; cf. Leibniz (1978b, §11 p. 603).

39 'Der Sündenfall wäre also ein Fall 'in die zeitliche Existenz' wegen der Unersättlichkeit. Aber das, was die Dinge selbst erschaffen, damit sind sie wieder nicht zufrieden etc." (Crocco et al, 2017, 13; "The Fall would be a fall 'into temporal existence' because of insatiability. However, things are again not satisfied with what they themselves create etc." [our translation]). Cf. also "satiatedness" in the remark from Max X quoted in footnote 56, p. 16 below.

40 Cf. the following passage from the context of (3): "[T]hat as many [things] as possible will come to be - . . this is the ultimate ground of variety (variatio delectat)" (Gödel 1995d, pp. 432-433, translation modified; Gödel 2016, XIV 104).
} 
multitude and variety. ${ }^{41}$ Moreover, as can be expected, enjoyment is interrelated with the "beautiful". 42

It should be noted that "positive", if conceived in a "moral aesthetic sense", as in the onto-theological axioms from 1970 (Gödel, 1995d, p. 404), obviously refers to "good" as well as to "beautiful". This is certainly a Platonic moment (see, e.g., Plato 1964-1978, VI, Republic 508E), which, on the other hand, once again points to Gödel's nonacceptance of Kant's (as he thinks) dubious systematics with respect to the interrelation of the practical and the aesthetical. $^{43}$

We will use the term 'enjoyment', like 'will', in a wider sense, as compatible with Gödel's monadological views. For instance, Gödel seems to assume that monads that are not living beings can experience pains (Wang, 1996, 9.1.8 p. 292 ), and thus, probably also enjoyment or pleasure. ${ }^{44}$ Gödel's remarks allow us to understand enjoyment, which is a part of a causation structure, as a conscious state of the fulfilment (satisfaction) of will in a realized perfection.

\subsubsection{God}

For Gödel, God is the cause ("last principle", Wang 1996, 315, quoted on p. 6 above) of the world as a whole, and does not have any further cause (God is "necessary in itself"). ${ }^{45}$ Each of God's decisions is "fixed in itself" ("an sich feststeht", actus primus, Gödel 2016, XIV 74). On the other hand, God comprises all and only the positive intended goals of our will, since 'to be God' is defined by Gödel as 'having each positive property', that is, each perfection $-G x={ }_{\text {def }} \forall X(\mathcal{P} X \rightarrow X x)$ (Gödel 1995d, p. 403; cf. also ca. 1941:

\footnotetext{
41 See Gödel (2016, XIV 76), where Gödel explains that, according to the "good principle", what was separated in an opposition becomes united, and he calls this unification (Vereinigung) harmony, in distinction to separation, which is disharmony. Cf. also in Gödel (2016, XIV 103) and Gödel (1995d, pp. 432-433) that "harmony" implies "more being than disharmony". For the harmony in nature, see, for instance, Gödel's example of the correspondence of a "whole 'organism", of an "electron event" to each small disturbance (Crocco et al, 2017, 10), the example of an accordance in a "dipole", where "the closer both parts are, the stronger the pairs would act" (Crocco et al 2017, 5; Bernard 2016), and the following example of accordance: "at the same angle, there is the same color" (Gödel 1995d, pp. 432-433; Gödel 1995d, XIV 104). Noticeably, Gödel complains of a lack of sufficient understanding of the concept of harmony (Gödel, 2016, XV, pp. 66-67).

42 Gödel implicitly relates enjoyment, as the opposite of sadness, with the beautiful: "[I]f there were a completely hopeless sadness, there would be nothing beautiful in it" (Wang, 1996, on 27.2 .1950 p. 43). Also, for example, "Slezak simply leaves out all the nonpretty, since it is not enjoyable to write about them" (Wang, 1996, on 17.3.1962 p. 44).

43 See Gödel's letter to Bernays from 1961 (Gödel, 1986-2003, IV, pp. 186-188).

44 Cf. "[E]lementary particles are a lower form of mind" (Wang, 1996, 9.4.12 p. 314; cf. 6.2.4 p. 191).

45 "Remark (Theology): The reflection: according to the Principle of Sufficient Reason the world must have a cause. This must be necessary in itself [an sich notwendig] (otherwise it would require a further cause)." (Gödel, 1995d, p. 430-431, Max XI; see Wang, 1996, p. 120). Because of the irrationality of will, we could understand that the complex: will - force - enjoyment, determined by the intended goals, does not, in general, possess some such "necessity in itself" that would guarantee the realization of positive values.
} 
$G(x) . \phi \in+\rightarrow \phi(x)$, Gödel, 1995d, p. 429). ${ }^{46}$ Thus, the causality that starts from our will, according to Gödel, is nothing else than the participation in God's creation, and therefore, God's causality is partly immediate and partly mediate, that is, realized through His own creatures. ${ }^{47}$

The existence of God, not being in general evident, requires an argument. As is well known, Gödel's various drafts on ontological proof of the existence of God from the 1940s to the 1970s are preserved (Gödel, 1995d, pp. 403-404, 429-435). Here, let us note that in Gödel's ontological proof, there is no explicit concept of causality ${ }^{48}$ - what is used for the formal presentation of the concept of God (e.g., in the ontological proof from 1970) is the above-mentioned definition of 'to be God' as 'to be an entity possessing all positive properties (perfections)' and an axiomatically described concept of positiveness.

In distinction to Kant's merely regulative and postulative ideas of God, God is for Gödel a constitutive part of an all-comprising causal structure. On the other hand, it seems that Kant's criticism of Leibniz's ontological proof, with insistence that Leibniz, within his proof, showed only the logical possibility of God, may have prompted Gödel essentially to change the proof of the possibility of God as to show the real possibility of God by means of the axiomatically described intuition of the concept of positiveness. Obviously, Gödel was not satisfied with Leibniz's proof based just on the conceptual simplicity and unanalysability of the "positive", which for Leibniz implies objective, causal priority (Futch 2008, pp. 110-114; Leibniz 1999a, p. 869; Leibniz 1999b, p. 872), but, on the contrary, wanted to analyse the "positive" as far as it is accessible to conceptual intuition.

\subsubsection{Time and space}

The causal meaning of time, as indicated in Gödel's remarks, consists in direction towards what is "better", in improvement, development, although, in

\footnotetext{
46 Cf. also Gödel's remark that God is not definable without the concepts of value ("Gott [ist] nicht ohne Wertbegriffe definierbar", Gödel, 2016, XIV 118). At the same time, "God" sometimes appears on Gödel's lists of primitive concepts (see above, p. 6). This indicates that the meaning of the concept "God", for Gödel, may not be exhausted by the above explicit definition (although this definition may be understood as a kind of description in causal terms by means of the concept of positivity). Accordingly, Gödel notes that we do not see as far through His essence ("weil wir das Wesen Gottes nicht so weit durchschauen"; Crocco et al, 2017, 62) (where what is the essence of God, according to Gödel's onto-theology, is precisely "to be God"). One further hint is that, although God is defined by having all positive properties, He is simple, in some not fully understood sense: "Das 'Einfache' an Gott is vielleicht, dass nur eine Art von Gut in höchster Intens <ität ist>?" (Crocco et al, 2017, 70; "The 'simple' on God is perhaps that only one sort of good is in the highest intensity?" [our translation]).

47 Cf. "weil wir durch unseren Willensfreiheit am Schöpfen Gottes teilnehmen (Gott schafft den Menschen sich zum Bilde)" (Gödel 2016, XIV 77; "because we participate through our freedom of will on God's creation (God creates the man as an image of Himself)" [our translation]). Cf. the remark quoted in footnote 26, p. 9. The idea of "created creators" in Gödel's theological view was drawn to my attention by Paul Weingartner. For his interpretation (in connection with Thomas Aquinas), see Weingartner (2016, p. 466).

48 See footnote 1, p. 2 above.
} 
the factual conditions of this world, time could also lead towards destruction (Gödel, 2016, XIV 19). The causation itself is perceived as the flow of time. ${ }^{49}$ Further, in an idealized sense, the past is, for Gödel, that which we cannot influence anymore ("worauf man nicht mehr einwirken kann", Crocco et al 2017, 22 ) and what is known (das Gewusste, Gödel 2016, XIV 19). On the other hand, the future is dependent on us (ideally, "what we can produce", "das von uns Erzeugbare"), and what is unknown, having its foundation (Begründung) in the past (Gödel, 2016, XIV 19, 17). In distinction, for example, to Leibniz' theory, time is, for Gödel, in itself non-objective, "no specific character of being", just our subjective way of the perceiving of the "causal structure" of the world (Wang, 1996, 9.5.10, 9.5.6, 9.5.5 on p. 320, 5.3.23 p. 168, 9.4.10 p. 313). On the ground of his understanding of relativistic theory, Gödel completely reduces the objective meaning of time to a timeless causal structure. ${ }^{50}$

As indicated in Gödel's remark (3), space is just the needed "nearness" (Nahesein) between components of a causation event, which makes causality possible. ${ }^{51}$ Space is an unstable structure (Crocco et al 2017, 10, 13-14; see Bernard 2016), which is being disturbed as well as stabilized by attractive and repulsive forces that are active in the vicinity of objects. ${ }^{52}$ Although mutual nearness implies a sort of "coexistence", which is at the core of the Leibnizian understanding of space (Leibniz, 1863, p. 18), it nevertheless cannot be concluded that Gödel would accept coexistence in Leibniz's sense as "simultaneity". ${ }^{53}$ It seems that Gödel has evolved in his conception of space from an objectivistic understanding of relativistic space-time, to monadological, essentially subjective, but still causally conceived space, as determined by drives and representations of monads (see Example 2, "Monadology", pp. 18-19 below).

\footnotetext{
49 "Das Wahrnehmen des 'Fließens' ist die direkte Wahrnehmnug der Erzeugung oder Ursachenrelation" (Gödel 2016, XIV 18; "The perception of 'flow' is the direct perception of the generating or causal relation" [our translation]).

50 See Gödel (1990b) and Yourgrau (2005, 1999). Also: "Causation is unchanging in time and does not imply change. .. Change is subjective in the Einstein universe" (Wang, 1996, 9.5 .9 p. 320); "As we present time to ourselves, it simply does not agree with fact" (Wang, $1996,5.3 .23$ p. 168). In distinction, for Leibniz, the linear order of time is based on the structure of spatio-causal events (see Leibniz 1863, p. 18, and Futch 2008, pp. 118-125).

51 "Being near = possibility of influence" ("Möglichkeit der Einwirkung") (Gödel 1995d, pp. 434-435; Gödel 2016, XIV 104). "Räumliche Nähe bedeutet offenbar: gegenseitige Beeinflussbarkeit" (Gödel 2016, XIV 19; "Spatial nearness means obviously: mutual influenceability" [our translation]). For the role of nearness in an "electron event", see Crocco et al (2017, 13-14).

52 Cf. also Gödel's remark: "We understand space only through the drive of the objects in space; otherwise we have no idea what space is" (Wang, 1996, 9.1.10 p. 292).

53 For Leibniz's understanding of time and space, see Futch (2008, pp. 118-125, 152-160).
} 
2.2.6 Life

According to remark (3), life is involved in will and enjoyment (daher das Leben). ${ }^{54}$ In a remark from Max X (Crocco et al, 2017, 7-8), Gödel describes the life of a bodily organism as an "imperfect structure", which is in "constant perfecting by means of what does not generate a complete perfection". ${ }^{55}$ In addition, Gödel speaks of life in a more general and fundamental sense (not just in the sense of material exchange) and distinguishes "very imperfect life" (in this world) and the "perfect life afterwards" (a reflection from the 1970s; Wang 1996, 9.4.19 p. 317). ${ }^{56}$ In these descriptions, we can recognize a will for perfection, and enjoyment, at first, in a partially realized perfection, with the perspective of an enjoyment in a more fully realized perfection. Gödel's remarks lead to an understanding of will as a choice of the perfections to be achieved, and enjoyment as the realization of these perfections. Non-enjoyment, as nonfulfillment of a chosen value, results in the will to continue further, towards new attempts of possible future fulfillment (continuation of life). What connects will and enjoyment is force as "tendency", conatus, like Leibnizian "live force" (Crocco et al, 2017, 44), ${ }^{57}$ which preserves the life structure by attracting what rebuilds the structure and by repelling what is destructive for it (see here footnote 55).

It should be noted that, for Gödel, life as a component of causation does not exclude mechanical causality. Gödel remarks that, for Leibniz, in "monads of the lowest kind" ("Monaden niederster Gattung"), and only in them, causality is purely mechanical, in the sense that what is currently happening in them depends just on what has previously happened in them (Crocco et al, 2017, 42 ). This should still involve a sort of "inner life" (at least according to Gödel's later reflections) - experience or representations (of objects in space), which are properties of monads in general (Wang, 1996, 9.1.8-9 pp. 291-292). ${ }^{58}$

\footnotetext{
54 As reproduced by Wang: "Will and enjoyment lead to life and affirmation and negation" (Wang 1996, 9.4.16 p. 315).

55 "Das Leben is offenbar eine unvollkommene Struktur, welche daher Materia von außen anzieht [nämlich Sauerstoff, Kohlenhydr<ate $\rangle$, Aminosäuren] und diese in Struktur aufnimmt. Die neue Struktur übt offenbar wieder eine 'Zerfallungskraft' auf sich selbst aus, sodass Harnstoff and Kohlensäure abgegeben werden" (Crocco et al, 2017, 7). ("Life is obviously an imperfect structure which because of that attracts matter from the outside [namely oxygen, carbohydrates, and amino acids] and receives them into structure. The new structure again obviously exerts a 'dissociation force' on itself, so that urea and carbonic acids are emitted." Cf. translations in Mertens 2016 and Bernard 2016, here slightly modified).

56 See also in an already mentioned remark from Max X: "Aber vielleicht gibt es die Speise, die für alle Zeit satt macht? Und den Atemzug, der alles weitere Atmen überflüssig macht" (Crocco et al 2017, 7-8; "However, maybe there is food that satiates for all time? And the breath that makes all further breathing superfluous"; see translations in Bernard 2016, p. 101, and Mertens 2016, p. 196, here slightly modified).

57 "Life force is a primitive element of the universe and it obeys certain laws of action" (Wang, 1996, 6.2.12 p. 193).

58 Gödel does not argue for animism, since for him, for example, the physical world "is inanimate" (Wang, 1996, 9.1.22 p. 295). But as soon as we have some whole built of matter, an additional, possibly animate, component is needed. "For something to be a whole, it has to have an additional object, say, a soul or a mind" (Wang 1996, 9.4.12 p. 314; cf. "In the
} 


\subsubsection{Form, matter}

The concepts of form and matter, which appear on Gödel's lists of primitive concepts, are recognizable in the above analysis in the relationship between force and space. According to Gödel, the instable space structure is "in a sense materia prima" (Crocco et al, 2017, 10, 14), which is being formed by a disturbing or stabilizing force (on Gödel's "hylomorphism", cf. Bernard 2016). Of course, the concept pair "form - matter" historically stems from Aristotle. ${ }^{59}$ The same should hold about "real time", since time is "in relativity theory ... like far and near in space" (Wang, 1996, 9.5.10 p. 320). The form-matter relationship can be recognized in our subjective perception of time in the relation of past and future (past as that which influences the future; see above, p. 15), although, as mentioned, this is just our "non-objective" way of representing the real causal structure.

\subsection{Examples of a causal structure}

Let us give a few examples of causation that clearly show the quinary causal structure sketched in remark (3).

Example 1. Bodily organism. Max X, Crocco et al (2017, 7-8).

In this remark (see footnote 55, p. 16), Gödel describes the life of a bodily organism, which consists in the constant exchange of matter between a living structure and its environment. The causal components of this structure can be discerned as follows:

1. will to be better, satiated, perfect;

2. force to attract and intake oxygen, carbohydrates, and amino acids, and (repulsive) "force of dissociation" to give off urea and carbonic acid;

3. perfectedness (to be improved, satieted), although without, or just possibly with, full perfection (perfect satiety, "perfect breath") [enjoyment];

4. living being as a creator created by God, re-creates its bodily living structure (see Crocco et al 2017, 12);

5. the direction of prior-posterior (time) in the experience of exchange of matter, and the nearness of the outside space (from which matter is attracted

case of matter, for something to be whole, it has to have an additional object", Wang 1996, 6.2 .9 p. 192).

59 If "drive" is understood as involving "force", Gödel's reflection about the understanding of space by means of the drive of objects in space (see footnote 52, p. 15 above) could also be seen as implying form-matter relationship. A sort of acceptance of Aristotelian primitive concepts does not contradict Gödel's Platonism. Besides "form" and "matter", concepts "substance" and "accident", too, can normally be found in Gödel's lists of primitive concepts. In an analysis of a possible Gödelian sense of these concepts it should be abstracted from Aristotelian realism, where concepts are only "parts or aspects of things", since Gödel, Platonically, accepts the separate objective "world" of concepts, which are "things" but not objects. See "Gibbs lecture" in Gödel (1995f, p. 321) and Gödel's distinction between objects and concepts (here, pp. 7 and 28). 
and into which it is given off) and the inside space (where matter is taken in, and from where it is given off).

Example 2. Monadology. We refer to Gödel's explicit account of monadology in Wang (1996) from the 1970s and elsewhere.

1. Will of monads is involved in Gödel's mentioning of the consciousness of a monad (Wang, 1996, 9.1.8, 9.1.9 on pp. 291-292, "inner life or consciousness") since "willing" is a way in which consciousness is "pointed" towards its intentional object (Wang, 1996, 5.3.28 p. 169). ${ }^{60}$ It should be noted that, in Max X, will is an inseparable part of attentive acts. ${ }^{61}$

2. Force of monads seems to be meant by their "drive" (appetitus), with attraction and repulsion of electrons as an example, obeying "laws of the interactions of monads". ${ }^{62}$

3. Gödel mentions that monads experience pain, which naturally implies that its opposite, enjoyment, too, should be included in their possible experience. This is clearly connected with Gödel's mentioning of happiness and sadness (miserability) in a human monad's life (Wang, 1996, 9.4.19-20 pp. $316-317) .{ }^{63}$

4. God has the role of "a central monad" (Wang, 1996, 9.1.2 p. 290, March 1976 p. 309) (see the comment below, immediately after 5.).

5. Although time, as mentioned, does not have for Gödel objective meaning, it seems to be essential for monads as minds: according to Gödel, "time is the only natural frame of reference" for mind (while space-time is natural for the physical world) (Wang, 1996, 9.5.1 p. 319). Gödel expected to be able to come to the understanding of time especially by a Husserlian phenomenological observation of the "working of the mind" (Wang, 1996, 9.5.3 p. 319). According to Gödel, what is space can be understood only by means of drives of objects, e.g., monads (like electrons), "in space", although monads themselves are not in space. What suggests itself, as mentioned earlier, is that space is just "nearness" (1954), in which drives of monads are actualized, and "contiguity" (Wang, 1996, 9.1.10 p. 292), which makes possible that "objects represent one another" (and, presumably, interact).

\footnotetext{
60 See footnote 25 on p. 9 above.

61 Cf. Crocco et al $(2017,59)$, with reference to Leibniz: "[M]an richtet die Aufmerksamkeit nur auf das, was dem, was man will, günstig ist" (emphasis added; "[O]ne directs the attention only on what is favourable to what one want" [our translation]).

62 E.g., Gödel, opposing Herbart, refers to "Leibnizian force" in the sense of the inner "principle of change" in monads (Gödel, 2016, XIV 83). Cf. Wang's interpretation: "Objects are, in the first place, the monads, whose appetition is force" (Wang, 1996, pp. 312, cf. pp. 311,310 ; appetition as "the tendency to go from state to state"). However, in Leibniz's Monadology, drives are conceived as "imitations" of God's will, which is, in turn, an infinite and perfect drive (Leibniz, 1978a, $\S 48$ p. 615). - As mentioned above, attraction and repulsion are non-Leibnizian aspects of Gödel's monadology (Bernard, 2016). The similar holds of "interactions of monads", if what is meant is not just an "ideal influence", since, according to Leibniz, no outer cause can influence the interior of a monad (Leibniz, 1978a, $\S 11$ p. 608, $\S 51$ p. 615). On monads "without windows", see Gödel's remark in Max X (Crocco et al, $2017,34)$

63 Also, according to Leibniz, there is under God's government no good action without reward, and no bad action without a punishment (Leibniz, 1978a, §90 p. 622).
} 
Monadology led Gödel to endorse the subjectivity of space, in particular in the sense of "mutual sensation of being near" ("for lifeless matter, too") with at least statistic objectivity. ${ }^{64}$

According to Gödel, his monadology should be Leibnizian in its "general structure" (with some differences as mentioned in footnote 62 on p. 18 , and on p. 12 above). For example, in Leibniz's monadology, we can find Gödel's first three causal components (will, force and enjoyment) as centred in God (the fourth component): (1) God is the "architect" and efficient cause of our "being", (2) He is the end of our will, and (3) only in Him we can find happiness. As to (1), God possesses creative force (puissance); regarding (2), God has goodness and will that always chooses what is better; regarding (3), God is most perfect and Himself most happy (Leibniz 1978a, §90 pp. 622-623, §55 p. 616, §48 p. 615; Leibniz 1978b, §16 p. 605, §18 p. 606, §9 pp. 602-603).

Let us note the difference between Gödel's accounts of electrons in Max $\mathrm{X}$ and in Wang (1996) (connected with the change in Gödel's conception of space). In distinction to the account in the 1970s, in Max X electrons are not monads, but "electron events", with their inner structure (they are composed); there, no consciousness, experience or representation in electrons is mentioned. An intermediate stance can be found in Gödel (2016, XIV 77), where Gödel is considering "entelechies" as possible "higher harmonizers" (for the establishing of unity) for elementary particles in quantum mechanics.

Since Gödel's system of primitive causally interpreted concepts is obviously theistic, and, moreover, since it is known that Gödel was dedicated to an in-depth reading of the Bible (as can be seen already from the Fall example above; see also Wang 1996, p. 51), we illustrate how his conceptual system might work in the following example.

Example 3. Creation of light (not from Gödel's text, Gen 1:1-5).

We paraphrase some parts of the text of Genesis 1 and emphasize the causal components following remark (3):

1. God wanted light - at first, it was dark ("darkness over the abyss") [will];

2. creative force of Word - "Then God said: Let there be light";

3. enjoyment of light - "... there was light. God saw that the light was good";

4. God, who is the cause "necessary in itself" and the cause of the world (cf. Max XI, p. 149, in Gödel 1995d, p. 430), is the first "subject" (agent) of the creation;

5. initially, there was the formless and shapeless earth, darkness, and "a mighty wind sweeping over the water" (materia prima, unstable space);

64 "Die räumlichen Beziehungen (auch die makroskopischen) bedeuten objectiv nichts, sondern gelten nur mit Bezug auf uns, und zwar a) sie bedeuten wenigstens stat. $<$ isch $>$ etwas Objektives* ( ${ }^{*}$ z.B. gegenseitig Empfinden des Naheseins)(aber Ausnahme z.B. wenn zwei Wesen voneinander träumen)" (Gödel, 2016, XIV 69). ("The space relations (the macroscopic ones, too) mean nothing objective, but hold merely with respect to us, and that, a) they mean at least statistically something objective* (*e.g., mutual sensation of nearness) (but the exception, e.g., when two beings dream about one another)" [our translation]). 
then, by the creation of light and the separation of the light from the darkness, there was the first day [time]; thereafter, by the creation of the sky with the separation of upper and lower waters, and by the creation of the land and the sea, space was formed and stabilized.

\subsection{Reduction to force (wish) and fact}

In the course of time Gödel aimed at a further reduction of the above causal structure. According to what Wang reports, Gödel's causality picture was in November 1975 quite succinct:

The meaning of the world is the separation of fact and force.

(Wang, 1996, 9.4.3 p. 311)

Assuming that the meaning of the world should be determined also with respect to thinking beings, and hence with respect to wish since "wish is force as applied to thinking beings, to realize something" (Wang, 1996, 9.4.3 p. 311), Wang reports of Gödel's following variant formulation:

The meaning of the world is the separation of wish and fact.

(Wang, 1996, 9.4.1 p. 309; pp. 287, 294)

Similarly: "The meaning of the whole world is the separation (and the union) of fact and wish" (Wang, 1996, 9.4.3 p. 311).

Here, a causal structure includes force (wish), fact, ${ }^{65}$ union, and separation. Causal components of remark (3) remain explicitly or implicitly included in the newly outlined structure. Thus, this structure can be described as consisting of

1. force to realize (to put into "being") some value or perfection as intended by will;

2. fact (encountered by force), possibly empirical (Wang, 1996, 9.4.9 p. 312), that is, related to the sensual space-time objects, ${ }^{66}$ or just some spatialtemporal, logical or mathematical structure, where "something" may not be realized (have "being"); 67

3. the separation of force and fact before the realization of a value (perfection);

65 Taking into account Gödel's remarks before the 1970s, "fact" should not be just "synthetic fact concerning sensations" ("empirical fact"), but also a fact "consisting in relations between concepts" (Gödel, 1995a, p. 351, ftn. 41, pp. 355, 356) and a mathematical fact (Gödel, 1995a, p. 337).

66 See, e.g., Gödel (1995f, p. 312, with ftn. 18) and Crocco et al (2017, 29).

67 Apparently, Gödel is in his ontology of force and fact primarily focused on the world of empirical facts (Wang, 1996, 9.4 .9 p. 312). However, it can be seen that, according to Gödel, concepts, too, i.e., "generalities" are a "fundamental aspect of the world" (Wang, $1996,9.1 .24$ p. 295). We will return to this in the following section, where we will outline a possible Gödelian causal account of the "conceptual world" (Wang, 1996, 9.2.10 p. 299, 9.4.18 p. 316). 
4. the union of force and fact after the realization of a value (perfection), with a "fulfilled wish", and thus enjoyment, which correspond to this union. ${ }^{68}$

Again, God, as the cause of the world, may be assumed as a force, first, separated from space at the beginning of the creation, and finally, as much as possible united with space at the end of the creation (with as much being as possible realized). Time of creation remains to be merely a subjective way that the created things perceive the creation.

It should be noted that "possibility" in this new scheme has a more important role than before. It seems to be for Gödel the next concept involved by the concepts of force and fact, since it is understood as the "synthesis" of being and non-being, and so the "synthesis" of force (which is directed to being of something) and fact (which lacks the being of what has to be realized). ${ }^{69}$ The concept of possibility will be analysed further below.

\section{From logical objectivism to logical causalism}

On the ground of Gödel's texts, in this section, a reconstruction of the logical aspect of foundational causal concepts is proposed, and some primitive logical concepts analysed with respect to their causal content. A Gödelian causal account of mind and understanding is outlined.

\subsection{Causal meaning of logical concepts in general}

The objective status of mathematical and logical truths is a well-known aspect of Gödel's Platonism. One basic philosophical result of the second incompleteness theorem is, according to Gödel, that logical concepts, for example, "all", cannot be defined "in terms of the meaning of "proof'" (Gödel, 1995f, p. 313), and, as mentioned above, that there are logical and mathematical "facts", in the sense that logical and mathematical concepts "form an objective reality of their own, which we cannot create or change, but only perceive and describe" (Gödel, 1995f, p. 320). Accordingly, concepts are objectively interrelated, forming a "conceptual space".70

In addition, Gödel envisages a further step, more "unpopular" than logical and mathematical objectivism (Platonism) in general, which would consist in showing that logical (and mathematical) objectivity has a causal structure, that is, in explaining and defining logical and set-theoretical concepts in terms of causality (see remark (3)). We follow Gödel's remarks and hints about how this could be conceived.

\footnotetext{
68 "A fulfilled wish is a union of wish and fact" (Wang, 1996, 9.4.3 p. 311).

69 See Wang (1996, 9.4.9-10 pp. 312-313).

70 Cf. "that the conclusion is implied by the premises is itself an objective fact concerning the primitive terms of logic" (Gödel, 1995a, p. 350, ftn. 40, emphasis added). As expressed in 1975, concepts "are related each in the other and form the "conceptual space'" (Wang, $1996,4.4 .7$, p. 149).
} 
As a preliminary, it should be noted that Platonism and causalism are connected in a natural way because of the Platonic causal conception of the participation of things in "ideas" (concepts). ${ }^{71}$ As is known, later Plato criticized the so called "doctrine of ideas" ("Platonism" in an ordinary sense) and searched for a solution through a complicated theory of dynamic interrelations between "ideas", and between "ideas" and things (e.g., in the dialogues Sophist and Parmenides; Gödel might refer to Sophist by mentioning Plato's paradox of falsehood, Crocco et al 2017, 21, ftn. ${ }^{72}$ ). Although a Platonic flavor can be felt on many places in Gödel's reflections, noticeable is Gödel's cautious and critical stance towards ordinary Platonism. ${ }^{73}$ As will be seen, contrary to ordinary Platonism, for Gödel, concepts (Platonic "ideas") are not objects and do not cause objects, although concepts are things, embedded in objectivity and its causal structures. On the other hand, contrary to Kant's criticism, concepts are not for Gödel merely subjective forms (such as time), but "constitute" true objects (not just appearances), and are perceived in a sort of causal interaction with mind (cf. p. 34, ftn. 113, below). Correspondingly, Gödel searched for a general theory of concepts with a possible scientific causal foundation, and for a phenomenological methodology of the perception of concepts and of the justification of primitive concepts, aiming at an axiomatic form in order to ultimately obtain an exact theory (cf. above Gödel's remark (3) on p. 6, and p. 7).

The step towards causal explanation of logical concepts seems to be for Gödel much harder than establishing Platonistic objectivism (once the incompleteness proof has been devised). The causal interpretation may be one of the possibilities connected with the result of Gödel's 1944 paper "Russell's mathematical logic" (Gödel, 1990d), according to which, even after simple theory of types and axiomatic set theory were developed, "many symptoms show only too clearly ... that the primitive concepts [of logic] need further elucidation" (Gödel 1990d, p. 140; Wang 1987, p. 311), that is, we dispose only with an "incomplete understanding of the foundations" (Gödel, 1990d, p. 140). In particular, Gödel emphasizes (in 1944) the insufficient distinctness of the concept of "concept" ${ }^{74}$ and in the 1970s he complains about intensional paradoxes as inherent in a general concept theory. ${ }^{75}$

\footnotetext{
71 For example, in his dialogue Phaedo, as indicated by a reviewer. See Plato (1964-1978, I, Phaedo 100B-101C). Platonic "idea" is, for Gödel, the Platonic counterpart of "concept" (Wang, 1996, 8.6.18 p. 277, cf. 5.3.15 p. 167).

72 Cf. Plato (1964-1978, VII, Sophist 239D-241B, 263B-C).

73 Cf. expressions like "a cautiously platonistic point of view" (Gödel, 1986-2003, vol. 4, letter to Bernays, pp. 308-309), "a kind of Platonism, which cannot satisfy any critical mind" (Gödel, 1995e, p. 50)

74 '[W]e don't perceive the concepts of 'concept' and of 'class' with sufficient distinctness, as is shown by the paradoxes" (Gödel, 1990d, pp. 139-140). According to Gödel, Russell brought to light "the amazing fact that our logical intuitions (i.e., intuitions concerning such notions as: truth, concept, being, class, etc.) are self-contradictory" (Gödel 1990d, p. 124; cf. Wang 1996, 8.5.1 p. 269).

75 "When we formulate the paradoxes in terms of concepts clearly defined for everything, we don't see what is wrong" (Wang, 1996, 8.6.23 p. 278).
} 
According to Wang's reports from the 1970s, Gödel was certain about at least some primitive logical concepts. The aim of the following two partial lists seems to be to present primitive concepts of logic (in the sense of concept theory):

negation, existence, conjunction, universality, object, (the concept of) concept, whole, meaning, and so on, (Wang, 1996, 9.1.26 p. 295)

negation, conjunction, existence, universality, object, the concept of concept, the relation of something falling under some concept (or of some concept applying to something), and so on.

(Wang, 1996, 8.6.17 p. 277)

Gödel especially emphasized the concept of existence as the "clearest" primitive concept, "with which we must begin as given". ${ }^{76}$ This still does not exclude the possibility that such concepts be axiomatically described from the aspect of their special causal role. In addition, it is not obvious that epistemological priority ("clearness") should always coincide with the logical, ontological or causal priority. ${ }^{77}$

\subsection{Basic logical concepts and causality}

We will, first, analyse in which sense causal concepts of will, force, enjoyment, God, time and space, for Gödel, could have some specific logical meaning. Secondly, we will consider particular logical concepts such as affirmation, negation, whole, part, subject, predicate, possibility, and necessity (Gödel mentions some logical concepts in the context of the remark (3)). Taking their logical meaning in a particular logic for granted, we will be interested in what could their foundational causal meaning, for Gödel, consist of, independently of a particular logic (cf. Gödel's "abstract" or "absolute" concepts). ${ }^{78}$ As far as Gödel's remarks allow, a preliminary will be outlined for a possible Gödelian causal theory of concepts.

\subsubsection{Logical meaning of basic causal concepts}

(1) For the logical meaning of will, let us turn to the assertive interpretation of the positive (see p. 10 above), according to which positive properties are

\footnotetext{
76 In a remark from 1975 according to Wang, Gödel says: "The notion of existence is one of the primitive concepts with which we must begin as given. It is the clearest concept we have. Even 'all', as studied in predicate logic, is less clear, since we don't have an overview of the whole world" (Wang, 1996, 4.4.12 p. 150).

77 Cf. Max X: "Die hellsten Sterne [deutlichsten Begriffe] scheinen nicht die grössten [objektiv grundlegendsten] zu sein, sondern diese werden durch Konstruktion aus den deutlichsten gewonnen [ein Weg, z. B. der Nominalismus]" (Crocco et al, 2017, 3; "The brightest stars [the most distinct concepts] do not seem to be the biggest ones [objectively most fundamental], but they are obtained by construction from the most distinct ones [one way, e.g., nominalism]" [our translation]).

78 See Gödel (1995c, pp. 382-385), Gödel (1990a, 272-273), and Gödel (1990c).
} 
understood as assertions (or "attributions", as Gödel puts it in the 1970s), and negative ones as privations. Thus, assertion should now be the proper intentional "object" of will. It should be noted that "pure 'attribution" (former "assertion") is in 1970 defined as a property having the disjunctive normal form with a disjunct without a negative conjunct (Gödel, 1995d, p. 404). Assuming that logic is connected with intellect (Verstand), it should be noted that, for Gödel, intellect has a "practical", volitive, aspect since the intellect is, in a judgement, making a choice between different possibilities, and should acknowledge ("grant the being to") what is actual (Gödel 2016, XIV 52-53; Crocco et al 2017, 58). ${ }^{79}$ Moreover, in Max IX (Crocco, 2016), Gödel describes concepts as "choosing" their objects to which they apply (this being the sense of Platonistic "participation" of objects in "ideas").

As to the logical meaning of the other ones of the five basic causal components, we add some further remarks.

(2) Gödel points out that concepts "correspond" to forces, although concepts are not themselves forces (forces are in the middle between concepts and individuals; Gödel, 2016, XV, p. 64). ${ }^{80}$ On the other side, epistemologically, concepts are parts of, and can be implicitly defined by, axioms, which, as Gödel sometimes implies, possess force: "[A]xioms force themselves upon us as being true" (Gödel, 1990e, p. 268), what dynamically describes "causal connection in the perception of concepts" (Wang, 1996, p. 189).

(3) Further, Gödel remarks that no "life-experience" (Erleben) corresponds to concepts (Gödel, 2016, 96). Yet he speaks about the perfection and beauty of "completely developed" parts of mathematics, and of the expected perfection of the "conceptual world" (Wang, 1996, 9.4.18 p. 316, 9.4.22 p. 317). Enjoyment (satisfaction) could be naturally associated with both of these perfections. Certainly, axioms or proven theorems could be naturally conceived as a fulfilment of an intellectual goal (knowledge, truth).

(4) 'To be God', in assertive interpretation, is defined in an entirely logical way - as 'having all and only assertions as properties' (these properties by themselves form a maximal consistent system).

(5) Time reflects (subjectively, in "thinking") a direction in combining of concepts: a present concept is being applied to a past (already given and known) one (a predicate to a subject matter), a later concept to an earlier (as if already given and known) one (Crocco et al, 2017, 2). In addition, the flow of time itself "corresponds", according to Gödel, to the "concluding" in God's intellect, that is, to the necessity of how the past (given premises) is conceptually being complemented by the future (conclusions to be drawn) (Gödel, 2016,

\footnotetext{
79 A broad discussion about the logical role of will, decision, and approval/disapproval developed in the second half of the 19th and the first half of the 20th century. A good insight into the problem could be obtained from Gödel's philosophy professor in Vienna, Heinrich Gomperz (1897, pp. 64-70).

80 This clearly shows a weakening of ordinary Platonistic causality of "ideas", and on the other hand, a causal strengthening of Kant's and phenomenological transcendentalism - a characteristic middle position Gödel aims at, e.g., in Gödel (1995c).
} 
XIV 18-20 pp. 6-7). ${ }^{81}$ Gödel sometimes speaks of a "logical space" (emphasis added), "concept space", or "space of ideas" ("Raum der Ideen", "logischer Raum", "Begriffsraum"), ${ }^{82}$ which indicates that relations among concepts (if concepts are put "near" to one another), could be conceived as forms of spatial (non-)coexistence, such as compatibility and non-compatibility (cf. $\diamond$ as compatibility in Gödel 1995d, pp. 403, 404).

\subsubsection{Affirmation, negation.}

Gödel's examples of a pair (dipole), electron event, bodily organism and created things (Crocco et al, 2017, 5-6, 7-8, 10, 12-15) clearly show how various structures, in their causal life (e.g., by means of their intended perfecting, attractive and repulsive forces, intake and emission, satiatedness and nonsatiatedness, etc.), affirm what contributes to the being of these structures, and negate what destroys them. ${ }^{83}$ Besides, since the consequences of what is wanted (intentional "object") and is being realized may themselves be wanted or unwanted, Gödel emphasizes that an additional "affirmation" (Bejahen) by a "decision" (will) is requested (Gödel, 2016, XIV 51-52).

Similarly, it could be said that the "life" of an axiomatic system is a causal "structure" where proofs affirm what belongs to the system (what could be taken into the system as its theorems), while disproofs negate what does not belong to it. Proving and disproving themselves are sometimes explicitly con-

\footnotetext{
81 Thus, Gödel not only endorsed Kant's idea of the subjectivity of time, which he extended (on the ground of the relativity theory) to the clear non-objectivity of time (see Gödel 1990b). He also stood for a version of temporal "schematism" applied to primitive logical concepts (for Kant, see especially Kant 1968, B 183-184). Cf. below on subject-predicate relationship and implication (pp. 29 and 31). However, Gödel emphasizes that this is only the form of the subjective aspect of logic ("thinking"), in distinction to the "form of objectively logical relationships" (Crocco et al, 2017, 2).

82 See Crocco et al $(2017,44,67,69)$ and Gödel (2016, XIV 99). On the distinction between concepts and Kantian (inexhaustible, direction-giving) ideas, see Wang (1996, pp. 268-269, 6.1.13 p. 188).

83 In the cosmological sense of the affirmation, the being as such should be affirmed in order to start establishing the structure of the world. Cf.: "The affirmation of being is the cause of the world [Das Bejahen des Seins ist die Ursache der Welt]. The first creature: to being is added the affirmation of being. ... as many [things] as possible will come to be ..." (Gödel 1995d, pp. 432-433, slightly modified translation, and Gödel 2016, XIV 104).
} 
ceived by Gödel as causal affairs. ${ }^{84}$ Using Gödelian justification logic tools ${ }^{85}$ (with a causal interpretation), it is possible to make affirmation and negation by proofs and disproofs explicit in the formulas of the shapes $t: \phi$ (' $t$ proves $\phi$ ') and $t: \neg \phi$ (' $t$ disproves $\phi$ ').

\subsubsection{Whole, part}

Gödel ascribes (in the 1970s) a fundamental role to the concepts of whole and part. $^{86}$

"Whole" is generally described as a divisible unity (Wang, 1996, 9.1.25 p. 295). For instance, sets (if not singletons) are just a "limiting case of wholes" since they "are unities which are just the multitude" (Wang, 1996, 9.1.28 p. 296). In distinction, a concept (if not a simple one, like a primitive concept), "is a whole in a stronger sense than sets; it is a more organic whole" (Wang, $1996,9.1 .26$ p. 295).

One aspect of the causal meaning of a whole seems to lie for Gödel in the composing and combining parts into a whole (Zusammensetzung, Kombination, Crocco et al 2017, 1, 2; but see Gödel 2016, XV p. 65). Logically, the whole-part relationship characterizes the content of a concept, where logical concepts are the "putty" that "holds together" (zusammenhalten) the components of a concept. This "holding < something $>$ together", which is, according to Gödel, "the formal, namely the structure", seems to imply a sort of "corresponding" force and causality ${ }^{87}$

\footnotetext{
84 E.g., Gödel speaks of the "causation in mathematics, in the sense of, say, a fundamental theorem causing its consequences" (Wang, 1996, 9.5.6 p. 320). Similarly, Wang reports that Gödel "... once said to me that there is a sense of cause according to which axioms cause theorems. It seems likely that Gödel has in mind something like Aristotle's conception of cause or aitia which includes both causes and reasons" (Wang, 1996, p. 120). Of course, in accordance with a reviewer's remark, one should trace the idea of reasons as causes further back to Plato. Cf., in particular, the stress on the unstable, changing and moving character of arguments ("reasons"), for instance, in the dialogue Euthyphron (Plato, 1964-1978, I, 11C-E); Gödel refers to this dialogue in the 1970s (Toledo, 2011).

It is a natural consequence of Platonistic objectivism to conceive reasons as causes, since the implication relation between reasons and consequents should also be understood as something objective, and hence, most naturally, as causation. Concepts, reasons, and causes, as well as logic, epistemology, and ontology, get intrinsically and systematically interconnected (the possibility of an ontological proof is one of the consequences).

85 See Gödel (1995h), Artemov and Yavorskaya (Sidon) (2011), and Fitting (2014). For a causal interpretation, see (Kovač, 2015).

86 "Whole and part ... are most fundamental in our conceptual system" (Wang, 1996, 9.1.24 p. 295).

87 "Insbesondere bilden bei der Analyse eines Begriffes in seine Bestandteile die logischen Begriffe 'den Kitt', welcher sie zusammenhält. In diesem Sinn sind sie das 'Formale', nämlich die Struktur der Bestandteile" (Crocco et al, 2017, 1, ftn.). ("In particular, in the analysis of a concept into its components, the logical concepts build the 'putty' which holds them together. In this sense, they are the 'formal', that is, the structure of the components" [our translation]). - Since, obviously, whole is a sort of numerical (not distributive) identity, Gödel counts it to "extensional" unity (characterized by "contact" or "partition") (Gödel, 2016, XV, pp. 57, 62).
} 
Another aspect of the causal meaning of a whole consists in the increasing of the "being" of parts by establishing their harmony. ${ }^{88}$ Hence, Gödel sometimes calls harmony ("agreement", Übereinstimmung) of parts "reality", and disharmony (nonagreement, Nichtübereinstimmung) of parts "privation" (a negative property) (Gödel, 2016, XIV 117). ${ }^{89}$

Continuing the comparison with justification logic (in its causal version), the whole-part relationship can be understood as reflected by the operators of application and sum. Application operation, $\cdot$, can be interpreted as expressing a harmonic "holding together" of parts $\phi$ and $\psi-t: \phi \rightarrow(u: \psi \rightarrow((c \cdot t) \cdot u):(\phi \wedge$ $\psi)$ ) (c being a logical reason for the axioms of the shape $\phi \rightarrow(\psi \rightarrow(\phi \wedge \psi)))$. Sum operation, + , allows disharmony and mutual exclusion of parts $\phi$ and $\psi$ $-t: \phi \rightarrow(u: \psi \rightarrow(d \cdot(t+u)):(\phi \vee \psi))$, with possibly $\psi=\neg \phi(d$ being a logical reason for the axioms of the shape $\phi \rightarrow(\phi \vee \psi)$ and $\psi \rightarrow(\phi \vee \psi))$.

\subsubsection{General, particular}

In the 1970s, Gödel also ascribes a fundamental role to the concepts of "the universal" and "the particular". 90

Gödel gives the following explanation of "the general" (a reflection from the 1970s; Wang 1996, 9.4.5 p. 312). He starts from the proposition:

Force is connected to objects and a concept represents repetition of objects,

and continues:

The general is that which holds the individual objects together.

In addition, Gödel states that "... since there is similarity, there are generalities" ("existence of concepts $\equiv$ existence of a similarity", Gödel 2016, XV p. 62 ). This seems to indicate that some (attractive) force "connected to objects" is needed to hold objects together, in correspondence with their repetition and similarity (i.e., partial identity, Gödel 2016, XV, p. 62; XIV 121). The "holding together" on the ground of similarity differs in meaning from the "holding together" of parts within a whole. ${ }^{91}$ Similarity, on which the general is based, is not just repetition (of a common trait in distinct objects), but,

\footnotetext{
88 Harmony implies "more being" than disharmony, which, in turn, means "cancellation" of being - if parts are in opposition ("disharmony"), their being is cancelled ("der Gegensatz der Teile hebt ihr Sein auf", Gödel 1995d, p. 432, Phil IX 104). For the relatedness of harmony to enjoyment, see p. 12 above.

89 It should be noted that the causal meaning of the whole-part relationship is evident in Kant's corresponding category of "reciprocal influence" (Wechselwirkung), "deduced" from the logical form of disjunctive judgement as a relation of (exclusive) disjunctive whole and its disjuncts.

90 "Generalities are just a fundamental aspect of the world. It is a fundamental fact of reality that there are two kinds of reality: universals and particulars (or individuals)" (Wang, 1996, 9.1.24 p. 295).

91 Cf. Max IX on concepts as what "holds the world together" ("hält ...zusammen") in Crocco (2016, p. 140, 142).
} 
in distinction to sets, obviously some stronger unity of objects. ${ }^{92}$ What Gödel might have in mind is that a general concept contains, besides some common mark, also the indication of ways it could "fall apart" and be further specialized (Gödel, 2016, XIV 89), that is, of the ways of its application.

On the other hand, the particular should, evidently, be understood from some "cause of the difference of things" (to hold things apart from one another; emphasis added) - and this is, according to the context of remark (3), properties. ${ }^{93}$

The causal structure of the "holding objects together" by generality can be nicely depicted by the generalization operator $g e n_{x}(t)$ borrowed from causally interpreted justification logic. The formula $t: \phi$, where $x$ does not occur free in $t$ (but can occur in $\phi$; the proviso is slightly different in justification logic proper), expresses the similarity of the causation of $\phi$ by $t$ irrespective of which object $x$ formula $\phi$ is about. Axiom scheme $t: \phi \rightarrow g e n_{x}(t): \forall x \phi$ allows for the generalization of $t$ to the general cause $\operatorname{gen}_{x}(t)$, which "holds together" all objects $x$ under the conceptual configuration $\phi$.

As already quoted, Gödel concluded that "causation is fundamental; it should also explain the general and the particular" (Wang, 1996, 9.4.5 p. 312). With the "general", Gödel arrives at the essence of a concept:

The general idea of concept is just generality.

(Wang, 1996, 8.4.22 p. 269)

It seems that it should be allowed to generalize Gödel's remarks on "general" and "particular" not only to first-order concepts (concepts of objects) but to concepts in general. ${ }^{94}$ However, Gödel confirms that, because of intrinsic reasons (intensional paradoxes), he did not come to some satisfactory general theory of concepts (pp. 32, 22).

Remark If we abstract from the intrinsic problems of a general concept theory (cf. Wang 1996, pp. 278-279), the distinctions "general - particular" and "whole - part", if taken with respect to the things (beings, unities) in general, can explain the motivation for Gödel's divisions of things, first, into concepts as universals, and objects as particulars (sets, monads, material/spacio-temporal objects), as well as, secondly, into wholes and simple things (e.g., monads, unit sets, empty set, primitive concepts). ${ }^{95}$

\footnotetext{
92 Gödel says that "a concept represents repetition of objects", but also that mere "multiplicity (or repetition) is mathematics, which does not take primary place in this scheme" (Wang, 1996, 9.4.5-6 p. 312).

93 "Property = cause of the difference of things" (Gödel 1995d, pp. 432-435; Gödel 2016, XIV 105). This certainly also reflects the Platonistic view of things as depending on (participating in) properties as concepts (Plato's "ideas").

94 "[A] concept $A$ applies to something $B$ (which may also be a concept)" (Wang, 1996, 8.6.18 p. 277). On self-applicability of concepts, see Wang (1996, 8.6.3 p. 274, 8.6.23 p. 278).

95 See Wang (1996, 9.1.25 p. 295, 9.1.27-28 p. 296, 8.6.25 p. 279).
} 


\subsubsection{Subject, predicate}

The way how our intellect "acknowledges" the actual in a judgement (p. 24 above) Gödel more precisely determines as the "transition" (Übergang) to the representation of an object that is the subject (Gegenstand) of predication. Thus, the directedness (Gerichtetsein) towards something "outer" (object), which is already given and known, is established (Gödel, 2016, XIV 39-40). This structure is temporally reflected in the past-present relationship, where a (given and known) subject (past) cannot be influenced on, and where, in turn, this subject influences what can be predicated of it (Crocco et al 2017, 22; Gödel 2016, XIV 17, 19). Thus, subject and predicate are connected in a causal unity ("both become one", the unity being expressed by est) (Crocco et al, 2017, 65). ${ }^{96}$

Additionally, if a subject is itself referred to by a subject concept (as in subject-predicate sentences of natural language or, for example, of Kantian logic), it can be noticed that, for Gödel, the subject (in "synthetic propositions"), or subject concept (in "analytic propositions"), "contain" (enthalten, "hold in") a predicate. This "containedness" (Enthaltensein) should also be causally conceived as a sort of logical "putty" (Gödel 2016, XIV 116-117; cf. footnote 87 on p. 26 above). ${ }^{97}$

\subsubsection{Necessity, possibility, implication}

In Phil XIV, the concept of necessity means that "something follows from mere concepts", and is synonymous with "understandability" (Verständlichkeit) (Gödel, 2016, XIV 118):

Necesarily $\phi \quad \Longleftrightarrow \quad$ it follows from mere concepts that $\phi$.

"Following" happens by means of axioms and rules, and axioms need not be tautologies ("reducible to $a=a$ ", "void of content"), but can themselves "follow from the meaning of the primitive terms under consideration" (Gödel, 1995f, pp. 320-321). In other words, "following", and thus necessity, obtain analytically, not just tautologically. Further, since "generality" and "whole", on which concepts are based, have a causal meaning (as outlined above), it follows that "necessity", too, should be based on the causal meaning of concepts, that is, exactly on the ways how they have to "hold together" their parts as well as the objects they refer to.

\footnotetext{
96 According to the previous analyses, unity is in general a goal intended by will (see p. 10 above), and its realization should be immanent to an applied "holding" force. Let us add that there is a connection of Gödel's temporal schematism with Kant's. In Kant's schematism of categories, "substance" (corresponding to "subject") is schematized by the persistence (unchangeability) in time, and "accident" (corresponding to predicate) by changeability (Kant, 1968 , B 183). Of course, past is unchangeable, and future seems to be changeable.

97 See Crocco et al $(2017,71)$.
} 
Gödel sometimes describes the dual concept possibility as "compatibility" of properties or of a "system of properties" (Gödel, 1995d, pp. 403, 404). ${ }^{98}$ In accordance with the concept of necessity, this should also be understood with respect to the meaning of primitive concepts, that is, analytically: ${ }^{99}$

Possibly $\phi \quad \Longleftrightarrow \quad \neg$ (it follows from mere concepts that $\neg \phi$ ).

Accordingly, the causal sense of possibility should be that there are ways something $(\phi)$ can be conceptually "held together".

In Phil XIV, Gödel makes the causal meaning of "possibility" more explicit by grounding it in the activity and free will, by means of which, even in cognition, "we" participate in God's creation and build the world out of concepts. As Gödel emphasizes, "an entirely passive being ... would have no real understanding of the concept of the possible" (Gödel, 2016, XIV 78, our translation). Conceptual possibility is part of the creation (where we participate through our activity and free will), which is obviously a causal affair. - In distinction, in the empirical world (and in the temporal schematism of conceptual world as well), as may be concluded from the analysis of the causal components in general, possibility consists (a) in the temporal directedness: something is possible on the ground of the past, and it is impossible to influence back on the past, as well as (b) in the spatial nearness (contiguity) of the causal components (in order to be able to interact). ${ }^{100}$

There is an essential distinction of Gödel's concept of necessity and Leibniz's concept, which is based on the principle of contradiction, and hence, reduces necessity (and the dual concept of possibility) to tautologies. ${ }^{101}$ This is the reason why the first part of Gödel's ontological proof (1970), that is, the proof of the possibility of a "God-like" being, is different from Leibniz's proof of the possibility of God. Gödel's proof is based on the axiomatic description of the second-order property of positivity, obtained from the intuition of the "positive", rather than just on the simplicity, unanalysability, and thus non-contradictoriness of "perfection".

"Modal collapse". What is (somewhat misleadingly) called "modal collapse" theorem $(\phi \leftrightarrow \square \phi)$ of Gödel's onto-theological system (e.g. from 1970, see Sobel 2004, pp. 134-135) does not cancel the conceptual distinction between possibility, necessity and actuality, but merely states what is causally expressed

\footnotetext{
98 The concept "possible, not necessary" is also encountered, in the sense of "compatibility" (cf. verträglich) of $\phi(A)$ as well as $\neg \phi(A)$ with the essence of the same "being" (Gödel, 2016, XIV 5). Cf. p. 25 above.

99 See, e.g., Crocco et al $(2017,41)$.

100 See footnote 51 on p. 15 above.

101 "When a truth is necessary, its reason can be found by analysis, resolving it into simpler ideas and simpler truths until we reach the primitives. ... And there are, finally, simple ideas, whose definition cannot be given. There are also axioms and postulates, in brief, primitive principles, which cannot be proved and which need no proof. And these are identical propositions, whose opposite contains an explicit contradiction" (cf. Leibniz 1978a, Monadologie, $\S \S 33,35$ p. 612 ; translation from Leibniz 1989, p. 217).
} 
by the "maximum principle for the fulfilling of wishes", that is, for the realization of each conceivable "good" (possibly, with all the "bad" of "this life" as a necessary precondition). ${ }^{102}$ Cosmologically expressed, this principle means that the "building up of the world" (which is a causal affair) should ultimately lead (as if at the end of time) to the "best possible" world. ${ }^{103}$ The realization of the maximum is, according to Gödel, due to the meaningfulness (rationality) of the creation of the world, and to the non-limited capacities of human learning and development to "attain a better existence" (Engelen 2016, pp. 171-172; Wang 1996 , p. $106,9.4 .8$ p. 312 , $9.4 .18-20$ pp. $316-317) .{ }^{104}$

Implication. One of the ways possibilites can themselves be included in a formal structure is implication. According to Gödel, implication, like a subjectpredicate proposition, expresses "containedness" (Enthaltensein), but in distinction, it is a logical "putty" between two "mere possibilities", one of which, the hypothesis, "contains" another one, the consequence. ${ }^{105}$ Here the hypothesis need not refer to something already given in the past (subject) but merely to something possible (maybe just in the future), and the hypothesis should be at least conceptually prior to its consequence. Thus, it seems that the causal dependence in an implication could be properly temporally reflected in the pair earlier-later. ${ }^{106}$

\subsection{Antinomies and causality}

The Gödelian causal account of logical primitive terms might throw some additional light on logical antinomies. The following three examples show how antinomies violate causal relationships conceived in a Gödelian way.

In the sentence $S$ : 'This sentence is false' of the Liar paradox, the subject term seems to be 'this sentence', that is, $S$ itself (' $x$ which is $S$ is false'). In the subject-predicate relationship, the subject ( $x$ which is $S$ ) should be already given (past) and known, unchangeable under the influence of the predicate (future). However, in sentence $S$, the subject changes under the influence of its predicate (the past-future structure of causality is violated): by the predicate "false", $S$, as the subject, becomes true, and as true, $S$ becomes false. Hence, sentence $S$ does not have a subject ( $S$ itself), and thus $S$ is not a given sentence.

Russell's antinomical concept $w$ : "to be a predicate that cannot be predicated of itself" contains conflicts of similarity and predication, and of partition

102 "[T] he short period of misery may even be necessary for the whole" (Wang, 1996, 9.4.20 p. 317).

103 On connections between the so-called "modal collapse" and Gödel's version of a "slingshot" argument from 1944, see Kovač and Świętorzecka (2015).

104 See below, p. 35, on the non-reducibility of mind to a machine.

105 See Gödel (2016, XIV 53, 117; cf. XV, p. 65).

106 Similarly, for Kant, the antecedent and the consequent in a "hypothetical judgement" have only the value of logical possibility ("problematic" modality) (Kant, 1968, B 100). Also, the temporal schema of the category of causality (corresponding to the hypothetical judgement) is a regular succession in time (Kant, 1968, B 183). 
and predication. (1) If $w$ should, by similarity, "hold together" (causality!) $w$ and everything else that is a predicate that cannot be predicated of itself, then $w$ becomes predicated of itself, and thus should not be "held together" with other predicates that cannot be predicated of themselves. If $w$ should not, by dissimilarity, "hold" $w$ together with everything that is a predicate that cannot be predicated of itself, then $w$ applies, that is, becomes predicated, to itself, and thus should be "held together" with all other predicates that cannot be predicated of themselves. Therefore, $w$ should hold itself by not holding itself, and vice versa, that is, $w$ is causally impossible. (2) A similar argument to (1) shows that the intended content of $w$ is causally impossible, since $w$ should "hold" itself as a part in its own content if and only if it does not "hold" itself as such a part.

For Gödel, there is an essential difference between the Liar and Russell's paradox. The first one is semantical and depends on language; it could be said that expression $S$ "says nothing". But the second one is intensional, independent of language. Despite the contradictions, paradoxically, it is still possible to found $w$ "perfectly reasonable" (Wang, 1996, 8.5.12 pp. 271-272). For instance, we can still speak about various self-applicable and non-self-applicable concepts.

Finally, it would be intereseting to ask if there is at all some concept of not being applicable to everything ("to every entity [which may be an object or a function (a concept)]", Wang 1996, 8.6.25 p. 279), that is, in Gödel's terms, of "non-regularity". Gödel's paradox (1972), as Wang named it, shows that this concept, too, leads to antinomy (Wang, 1996, 9.6.24-25 p. 279) and is, on the present analysis, causally untenable. As reported by Wang, Gödel introduced a "dot" function, roughly, "regularity" of a concept (of a function $f$ ), according to which $f . x=f(x)$ if $f$ is regular, otherwise $f . x=0$, and a sort of negation, $E$, according to which $E(x)=0$ if $x \neq 0$, otherwise $E(x)=1$. Clearly, $E(x) \neq x$. Since $E$ is regular,

$$
E(x \cdot x) \cdot E(x \cdot x)=E(E(x \cdot x) \cdot E(x \cdot x)),
$$

despite the fact that, in general, $E(x) \neq x$. This result means that the regularity of non-regularity of $x, E(x . x) . E(x . x)$, gives its own negation, $E(E(x . x)$. $E(x . x)$ ), and vice versa, which is logically-causally untenable (similarly to Russell's $w)$. Note that $E(x \cdot x)=1$ simply means non-regularity of $x, x \cdot x=0$, not necessarily non-self-applicability of $x(x . x$ may give 0 even if $x(x)$ holds - non-regularity of $x$ suffices for value 0$) . E(x . x)=0$ means regularity of $x$. Thus, $E(x \cdot x) \cdot E(x \cdot x)=1$ means regularity of $E(x . x)$, that is, the regularity of non-regularity of $x$. Therefore, the question whether "non-regularity of $x$ " is applicable to each $x$ (i.e., whether "non-regularity of $x$ " is regular) is antinomic, and the sole concept of such a regularity would be a violation of logical causality. This is an indication that, although we, with not quite clear intuition, refer to the "concept of concept" (Wang 1987, p. 297; Wang 1996, 8.4.17 p. 267), its range (the domain for the regularity function) does not form a set. 


\section{4 "Function" of a category in general}

Let us now turn to the primitive logical concepts in general on the ground of Gödel's remark about Kant's categories (understood in (3) as logical concepts). ${ }^{107}$ Gödel's description of Kantian "function" of a category in general, if analysed a bit closer, reveals some similarities with the causal structure described in remark (3)

... the function of both [the concept of set and the categories of pure understanding in Kant's sense] is "synthesis", i.e., the generating of unities out of manifolds (e.g., in Kant, of the idea of one object out of its various aspects).

(Gödel, 1990e, p. 268, ftn. 40)

This description can be, somewhat loosely, connected with the five causal components of (3) as follows: (1) The "function" of categories could be conceived as presupposing some will (in Kant, it is just consciousness ${ }^{108}$ ), directed to a unity. ${ }^{109}$ (2) This unity should be established by an activity of "generating", "synthesis", as if presupposing some forming "force" to carry out this activity. ${ }^{110}$ (3) The function of unity is "satisfied" by an eventually generated concept of one object. (4) Some subject ("created creator") should be assumed that carries out this synthetic activity (for Gödel, it could be "active intellect", for Kant, it is "I", just a formal thinking subject). ${ }^{111}$ (5) What is presupposed is also a "manifold", "various aspects" (as already given before synthesis, for Kant, in space and time) that are being united into the concept of an object.

We will now show that a causal interpretation of Kantian synthetic function (whether it is the interpretation just outlined, or some similar one) can be confirmed by Gödel's explicit views. According to Gödel, the above intuitions of a functional synthetic activity should not be conceived as "something purely subjective", but "may represent an aspect of objective reality". This reality need not be sensibly given: the "presence [of 'abstract elements'] in us may be due to another kind of relationship between ourselves and reality", distinct from "actions of certain things upon our sense organs" (Gödel, 1990e, p. 268). ${ }^{112}$ Such "relationship" is in another place more precisely determined as "a causal

107 See footnote 14 on p. 6 above.

108 Cf. footnote 61 on p. 18 above.

109 "By a function ... I understand the unity of the action of ordering different representations under a common one" (Kant, 1968, B 93). Kant speaks, correspondingly, of the "function of unity" in a judgement containing a predicated concept - for example Kant (1968, B 94).

110 Cf. Gödel's expression like "forming of unities" (Wang, 1996, 8.3.1 p. 260) or: "we form our ideas" of objects (Gödel, 1990e, p. 268, emphasis added). Cf. pairs force - space and form - matter above in subsections 2.2 .5 and 2.2 .7 .

111 Gödel understands "I" (Ich) as an active ("efficient") principle (das wirkende Prinzip). See Engelen (2016, p. 179, ftn. 33, Max VI 381). For the active intellect, see footnote 113, p. 34 below.

112 "Kantian intuition is too weak a concept of idealization of our real intuition. I prefer a strong concept of idealization of it. ... Understanding a primitive concept is by abstract intuition" (Wang, 1996, 7.1.13 p. 217). Cf. also in Gomperz (1897, pp. 86-103). 
connection in the perception of concepts". ${ }^{113}$ Accordingly, the generating of unities, that is, the synthesis of a manifold in the concept of one object, may be part of a causal structure of "objective reality", which includes a causal interrelationship between the objectivity and our mind. Therein, our mind has an active causal role, and is at the same time influenced by objectivity through the perception of concepts. First, what our mind is actually doing, according to Gödel, is "singling out", "selecting" (defining, determining), objects "out of objectivity". ${ }^{114}$ On the other hand, the singling out of objects is restricted by the represented objectivity: not every manifold can be united at will in one object, for instance, because of possible inconsistencies. ${ }^{115}$ Finally, once the objects are selected, their relations become a determined part of a causal structure (Wang, 1996, p. 303-304).

\subsection{Causal understanding}

Besides a Turing machine, which can be designed so as to write all the theorems of a given well-defined axiomatic system (Gödel, 1995f, p. 308), Gödel had in mind some non-mechanical procedure of understanding (intuiting) concepts (especially abstract ones) in order to write down new axioms "explicating" these concepts. It should be noted that a Turing machine itself can be easily put in correspondence with the causal structure of remark (3): (1) it is based on a "will" which is "remembered" in a finite number of internal states (with associated instructions) to possibly compute some function $f\left(x_{1}, \ldots, x_{n}\right) ;(2)$ this computation is carried out by the "force" of a machine that is capable

113 "I believe there is a causal connection in the perception of concepts. ... Already nô̂s in Aristotle is a causal affair"; "the active intellect works on the passive intellect which somehow shadows what the former is doing and helps us as a medium" (Wang 1996, 7.3.14 p. 235, 6.1.22 p. 189, emphasis added). Eva-Maria Engelen has shown that Gödel's reception of Aristotle's doctrine of the "intellect" is mediated through Thomas Aquinas' commentary on Aristotle's De Anima; see Engelen (2013). Cf. also: "Concepts are not the moving force of the world but may act on the mind in some way" (Wang, 1996, 4.4.7 p. 149, emphasis added). - There is Husserl's, to some extent analogous, distinction between "active" and "passive genesis" of a transcendental subject ("I"); i.e, new objects are being "constituted" by active genesis on the ground of objects already given in the passive genesis. Although Husserl concedes, in the broadest sense of the word, "causal" character of the genesis of the transcendental "I", he prefers, in parallel with psychology, to speak about "motivation", this also "in contrast" to causality as pertaining to reality, which "transcends" the phenomenological sphere (Husserl 1995, §38 pp. 79-82, §37 p. 77; Husserl 2002, p. 89 with ftn. 1).

114 "Out of objectivity we define objects in different ways. Faced with objectivity, how to single out objects is your own child. ... [I]n physics objects are almost uniquely determined by objectivity, if you want to do it in the 'natural' way" (Wang, 1996, 9.2.40 p. 303). However, "there is a large gap between objectivity and objects: given the fact of objectivity, there may be other possibilities of selecting objects which we don't know yet" (Wang, 1996, 9.2.43 p. 304). This might be a late shape of an earlier view (Max IX) on concepts as "choosing" their objects (Crocco, 2016).

115 "Some pluralities can be thought together as unities, some cannot. Hence, there must be something objective in the forming of unities" (Wang, 1996, 8.3.1 p. 260). Correspondingly, Gödel mentions "absolutely infinite or inconsistent multitudes" leading to a contradiction, in distinction to a "consistent multitude" (Wang, 1996, 8.3.6 p. 261). 
of reading, writing, erasing, moving, and changing its internal states, according to the instruction at a given internal state; (3) the computational task is "satisfied" when the machine halts in a standard final configuration; (4) the whole computing event depends on the designer ("creator") of the Turing machine; and (5) the "space" in which the computation is being carried out, in some (possibly infinite) sequence of time moments, is a (possibly infinite) tape where initially the arguments are written for which the function should be computed. ${ }^{116}$

It was a consequence of Gödel's incompleteness theorem and of his epistemological optimism ("rationalism") that, "likely", "working of the mind" cannot be reduced to the working of finite machines, since, "if the mind were a machine", mind could not "understand its own mechanism" (e.g., its own consistency), and there would be "absolutely unsolvable" number-theoretic questions (not just for a given arithmetic system, but "for the human mind" at all). ${ }^{117}$ Accordingly, Gödel conceived human mind as "constantly developing" towards the infinity of abstract concepts (terms), of their precision, and of mind's internal states.

As previously mentioned, according to Gödel's idea of causality as the fundamental concept, the understanding of concepts should be a sort of reduction of their meaning to causal terms. ${ }^{118}$ Thus, the understanding of the understanding of concepts itself should be a sort of reduction of understanding to causal terms, and so, to the understanding of human mind (which is the agent of understanding) by means of some non-mechanical counterpart of a Turing machine. On the basis of Gödel's remarks, one option that might be taken into account is Gödel's picture of a causal structure with the "active intellect" working on the "passive intellect" (see above footnote 113 on p. 34).

Following this approach and relying on or extending slightly what may be found in Gödel's remarks, we could distinguish in the structure of the understanding of a human mind (1) an initial intention (will) directed towards the understanding of some concept, with the growing number (converging to infinity) of "distinguishable states of mind" carrying this intention; (2) the capacity ("force") of "effective thinking", for example, to attend to how we use a concept, to idealize and disregard "the imprecision in what is actual", to

116 For the importance of Turing's informal but rigorous clarification of the concept of computability by means of a Turing machine, see in Kennedy (2014): the precise general notion of a formal system was established only on the ground of Turing's "sharpening of intuition" in his "informal analysis" of the concept of mechanical procedure. See, e.g., Gödel (1990c) and Gödel (1986, p. 195, note from 1963).

117 See Wang (1996, 6.1.8 pp. 186-187) and Gödel (1995f, p. 310). Cf. "mind is not mechanical"; i.e., "evident" mathematical axioms "cannot be embodied in a finite rule" (Wang, 1996, 6.1.10 p. 187). - Here is an essential difference from Leibniz: Leibniz's "universal characteristic", according to Gödel, cannot exist, because "any systematic procedure for solving problems of all kinds must be nonmechanical" (Wang, 1996, 6.3.16 p. 202). However, see Gödel (1990d, pp. 140-141).

118 "We perceive objects and understand concepts. Understanding is a different kind of perception: it is a step in the direction of reduction to the last cause" (Wang, 1996, 7.3.12 p. 235). Cf. also: "Sets are objects but concepts are not objects" (Wang, 1996, 7.3.12 p. 235). 
repeat ${ }^{119}$ - starting from the attention to a mechanical procedure; ${ }^{120}$ (3) a satisfying state of the understanding of a concept, reached in the explication of the concept by axioms (or just by its definition); ${ }^{121}$ (4) God and the active intellect (the active intellect is believed by Gödel to be physically located in some place in the brain ${ }^{122}$ ), which is God's agent; ${ }^{123}$ they create and "hold together" the causal structure of understanding; (5) "passive intellect" (having no specific location in the brain; see Engelen, 2016), on which the "active intellect" works (as on a "tape"), with some data recorded, and otherwise "blank".

The main difference between mind and machine is, according to Gödel, consciousness, which is "connected with one unity", in contrast to a machine, which is "composed of parts" (Wang, 1996, 6.1.21 p. 189). ${ }^{124}$ Perhaps exactly this possibility of "holding", in consciousness, a whole understanding procedure united by means of the connectedness with "one unity" is what makes it possible for a human mind to obtain the evidence of the axioms that would otherwise inevitably remain undecided. This in distinction to a machine, which, as divided into a finite number of parts, can lose the whole of the procedure from its "attention" (halting problem).

Whereas the causal procedure of a Turing machine is easily learnable, the procedure of the functioning of the understanding mind while explicating concepts, according to Gödel, is highly internal and personal, ${ }^{125}$ and so even hardly learnable from others. We are far from being able to describe exactly a procedure of the understanding of concepts. For help, Gödel returns to phenomenology and Kant. ${ }^{126}$ The intention is that by further perfecting the phenomenological approach, the learning of a procedure of concept understanding

\footnotetext{
119 "Effective thinking" consists in "introspection and correct thinking", and it mainly consists in paying attention to "what you have to disregard": "you have to know what to leave out; this is the essence of effective thinking" (Wang, 1996, 9.2.4 p. 298). See also Wang (1996, 9.2 .19 p. $300,9.2 .22$ p. 301), and p. 2 above.

120 "[A]sking the right questions on the basis of mechanical procedure" (Wang, 1996, 6.3.15 p. 200).

121 It is not a concept itself that is the effect of understanding, but the axiomatic explication of the concept. Cf. "[I]dealization ... is not the cause of the concepts" (Wang, 1996, 9.2.19 p. 300).

122 See Wang (1996, 7.3.5 p. 233, 7.3.13-15 p. 235). This may be connected with Gödel's idea that our brain could be a "computing machine connected with a spirit" (Wang 1996, 6.1.19 p. 189; Wang 1996, 6.1.14 p. 193).

123 Cf. "The reason ... as an advisory being inherent to us", which would be in a sense, "the 'object' or at least the cause of our conceptual cognition". Further, the "advisory reason"

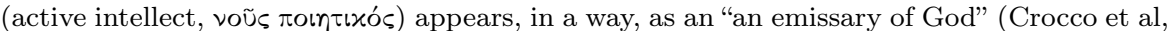
2017, 86, our translation and emphasis).

124 According to Leibniz, perception, however indistinct, is "inexplicable" by a machine, because what is found in the interior of a machine are just "pieces that push on one another" (Leibniz, 1978a, $\S 17$ p. 609, emphasis added).

125 Cf. voũs as "highest liveliness [höchste Lebendigkeit] (namely person)" (Crocco et al, 2017,87).

126 "The understanding of the system of primitive terms and their relationships cannot be transferred from one person to another. The purpose of reading Husserl should be to use his experience to get to this understanding more quickly" (Toledo, 2011, p. 200). See also Wang (1996, 5.3.28-31 pp. 169-170). For the phenomenological approach, independently of the causality concept, see, e.g., section 6 of Tieszen (2016).
} 
could be further improved, enabling us to acquire a more precise knowledge of how to achieve a possible axiomatic description of concepts.

Acknowledgements This work was supported by the Croatian Science Foundation under the project IP-2014-09-9378.

Works of Kurt Gödel used with permission of the Institute for Advanced Study. Unpublished Copyright Institute for Advanced Study. All rights reserved.

The author is grateful to Professor Gabriella Crocco (Aix-Marseille University) for permission to quote Gödel's Max Phil notebooks from the transcription of Max Phil X in Crocco et al (2017), from the draft transcriptions of notebooks Phil XIV and Max XV in Gödel (2016), and from Crocco and Engelen (2016a), as well as to add or slightly modify the translations of the quotations. In particular, thanks are due to Gabriella Crocco and to Anaïs Mauriceau (Library Granger-Guillermit at the Aix-Marseille University) for the availability of the above-mentioned draft transcription (Gödel, 2016).

The author would like to thank the audiences of a seminar at the Department of Philosophy of the Cardinal S. Wyszyński University, Warsaw, May 2013, and of the conference Kurt Gödel Philosopher: From Logic to Cosmology, Aix-en-Provence, 11-13 July 2013, where initial drafts of the paper were presented, for valuable comments and discussions.

\section{References}

Artemov S, Yavorskaya (Sidon) T (2011) First-order logic of proofs. Tech. Rep. TR-2011005, CUNY Ph.D. Program in Computer Science

van Atten M (2015) Essays on Gödel's Reception of Leibniz, Brouwer, and Husserl. Springer, Cham, Heidelberg, etc.

van Atten M, Kennedy J (2003) On the philosophical development of Kurt Gödel. Bulletin of Symbolic Logic 9:425-476

Audireau É (2016) Gödel: From the pure theory of gravitation to Newton's absolute, pp 57-79. In: Crocco and Engelen (2016a)

Bernard J (2016) From the physical existence of tuples to quantum materia prima, pp 81-105. In: Crocco and Engelen (2016a)

Crocco G (2016) Sinn/Bedeutung and intension/extension in Gödel's Max Phil IX, pp 127-152. In: Crocco and Engelen (2016a)

Crocco G, Engelen EM (eds) (2016a) Kurt Gödel Philosopher-Scientist. Presses Universitaires de Provence, Aix-en-Provence

Crocco G, Engelen EM (2016b) Kurt Gödel's Philosophical Remarks (Max Phil), pp 33-54. In: Crocco and Engelen (2016a)

Crocco G, van Atten M, Cantù P, Engelen EM (2017) Kurt Gödel Maxims and Philosophical Remarks Volume X. URL https://hal. archives-ouvertes.fr/hal-01459188

Engelen EM (2013) Hat Kurt Gödel Thomas von Aquins Kommentar zu Aristoteles' De Anima rezipiert? Philosophia Scientiae 17:167-188

Engelen EM (2016) What is the link between Aristotle's philosophy of mind, the iterative conception of set, Gödel's incompleteness theorems and God: about the pleasure and the difficulties of interpreting Kurt Gödel's Philosophical Remarks, pp 171-188. In: Crocco and Engelen (2016a)

Fitting M (2014) Possible world semantics for first order LP. Annals of Pure and Applied Logic 165:225-240 
Futch M (2008) Leibniz's Metaphysics of Time and Space. Springer

Gödel K (1986) On formally undecidable propositions of Principia Mathematica and related systems I, pp 145-195. Vol 1 of Gödel (1986-2003)

Gödel K (1986-2003) Collected Works, vol 1-5. Oxford University Press, New York, Oxford

Gödel K (1990a) On an extension of finitary mathematics which has not yet been used, pp 271-280. Vol 2 of Gödel (1986-2003)

Gödel K (1990b) A remark about the relationship between relativity theory and idealistic philosophy, pp 202-207. Vol 2 of Gödel (1986-2003)

Gödel K (1990c) Remarks before the Princeton bicentennial conference on problems in mathematics, pp 150-153. Vol 2 of Gödel (1986-2003)

Gödel K (1990d) Russell's mathematical logic, pp 119-141. Vol 2 of Gödel (1986-2003)

Gödel K (1990e) What is Cantor's continuum problem (1964), pp 254-270. Vol 2 of Gödel (1986-2003)

Gödel K (1995a) Is mathematics syntax of language?, pp 334-362. Vol 3 of Gödel (1986-2003)

Gödel K (1995b) Lecture on rotating universes, pp 269-287. Vol 3 of Gödel (1986-2003)

Gödel K (1995c) The modern development of the foundations of mathematics in the light of philosophy, pp 374-387. Vol 3 of Gödel (1986-2003)

Gödel K (1995d) Ontological proof / Appendix B: Texts relating to the ontological proof, pp 403-404, 429-437. Vol 3 of Gödel (1986-2003)

Gödel K (1995e) The present situation in the foundations of mathematics, pp 45-53. Vol 3 of Gödel (1986-2003)

Gödel K (1995f) Some basic theorems on the foundations of mathematics and their implications, pp 304-323. Vol 3 of Gödel (1986-2003)

Gödel K (1995g) Some observations about the relationship between theory of relativity and Kantian philosophy, pp 230-259. Vol 3 of Gödel (1986-2003)

Gödel K (1995h) Vortrag bei Zilsel, pp 86-113. Vol 3 of Gödel (1986-2003)

Gödel K (2016) Volume XIV of the Max Phil notebooks, draft, Gabriella Crocco (Editor-in-chief), Mark van Atten, Paola Cantù, Eva-Maria Engelen (eds.), contains Philosophy Notebook "Max XV, Letztes"

Gomperz H (1897) Zur Psychologie der logischen Grundtatsachen. Deuticke, Leipzig and Wien

Husserl E (1995) Cartesianische Meditationen, 3rd edn. Meiner, Hamburg

Husserl E (2002) Ideen zu einer reinen Phänomenologie und phänomenologischen Philosophie. Niemeyer, Tübingen

Kant I (1968) Kritik der reinen Vernunft, 2nd ed. 1787, Kants Werke, vol 3 (1st ed. in vol. 4). de Gruyter, Berlin

Kant I (1998) Critique of Pure Reason. Cambridge University Press, Cambridge, UK, transl. by P. Guyer and A. W. Wood

Kennedy J (2014) Gödel's 1946 Princeton bicenntenial lecture: an appreciation. In: Kennedy J (ed) Interpreting Gödel: Critical Essays, Cambridge University Press, Cambridge, UK, pp 109-130

Kovač S (2008) Gödel, Kant, and the path of a science. Inquiry 51:147-169 
Kovač S (2012) Modal collapse in Gödel's ontological proof. In: Szatkowski M (ed) Ontological Proofs Today, Ontos, Frankfurt etc., pp 323-343

Kovač S (2015) Causal interpretation of Gödel's ontological proof, pp 163-201. In: Świętorzecka (2015)

Kovač S, Swiętorzecka K (2015) Gödel's 'slingshot' argument and his ontotheological system, pp 123-162. In: Swiętorzecka (2015)

Leibniz GW (1863) Initia rerum mathematicarum metaphysica. In: Gerhardt CI (ed) Leibnizens mathematische Schriften, vol 3, zweite Abt., Schmidt, Halle, pp 17-29

Leibniz GW (1978a) Monadologie. In: Gerhardt CI (ed) Die philosophischen Schriften, vol 6, pp 607-623, transl. in http://www.earlymoderntexts . com/pdf/leibmona.pdf

Leibniz GW (1978b) Principes de la nature et de la grâce, fondés en raison. In: Gerhardt CI (ed) Die Philosophischen Schriften, vol 6, pp 598-606

Leibniz GW (1989) Philosophical Essays. Hackett, Indianapolis and Cambridge, transl. and ed. by R. Ariew and D. Garber

Leibniz GW (1999a) Definitiones: ens, possibile, existens. In: Leibniz (1999c), pp 867-870, http://www . uni-muenster .de/Leibniz/DatenVI4/VI4a2. pdf

Leibniz GW (1999b) Definitiones. notiones. characteres. In: Leibniz (1999c), pp 870-879, http://www . uni-muenster.de/Leibniz/DatenVI4/VI4a2 . pdf

Leibniz GW (1999c) Sämtliche Schriften und Briefe. Philosophische Schriften, vol VI 4. Akademie Verlag, Berlin

Mertens A (2016) Gödel's distinction between objective and subjective concepts: taken from the analysis of the remark on page 16 in the Max Phil XI, pp 189-201. In: Crocco and Engelen (2016a)

Plato (1964-1978) Plato in Twelve Volumes, vol 1-12. Harvard University Press and Heinemann, Cambridge [Mass.] and London

Reich K (1948) Die Vollständigkeit der kantischen Urteilstafel. Schoetz, Berlin

Sobel JH (2004) Logic and Theism: Arguments For and Against Beliefs in God. Cambridge University Press, Cambridge, UK, etc.

Świętorzecka K (ed) (2015) Gödel's Ontological Argument: History, Modifications, and Controversies. Semper, Warszawa

Tieszen R (2016) Leibniz, Husserl and Gödelian monadology, pp 447-463. In: Crocco and Engelen (2016a)

Toledo S (2011) Sue Toledo's notes of her conversations with Gödel in 1972-5. In: Kennedy J, Kossak R (eds) Set Theory, Arithmetic and Foundations of Mathematics: Theorems, Philosophies, Association for Symbolic Logic and Cambridge University Press, Ithaka, NY, and Cambridge, UK, pp 200-207

Wang H (1987) Reflections on Kurt Gödel. The MIT Press, Cambridge, Mass.

Wang H (1996) A Logical Journey: from Gödel to Philosophy. The MIT Press, Cambridge, Mass.

Weingartner P (2016) The need for pluralism of causality. Logic and Logical Philosophy 25:461-498 
Yourgrau P (1999) Gödel Meets Einstein: Time Travel in the Gödel's Universe. Open Court, Chicago

Yourgrau P (2005) A World Without Time: the Forgotten Legacy of Gödel and Einstein. Basic Books, New York 